\title{
Universiteit
}

Leiden

The Netherlands

\section{(In)definiteness, polarity, and the role of wh- morphology in free choice}

Cheng, L.L.; Giannakidou, A.

\section{Citation}

Cheng, L. L., \& Giannakidou, A. (2006). (In)definiteness, polarity, and the role of wh-morphology in free choice. Journal Of Semantics, 23(2), 135-183. doi:10.1093/jos/ffl001

Version: Publisher's Version

License: Licensed under Article 25fa Copyright Act/Law (Amendment Taverne)

Downloaded from: https://hdl.handle.net/1887/3247607

Note: To cite this publication please use the final published version (if applicable). 
Journal of Semantics 23: 135-183

doi:10.1093/jos/ffl001

Advance Access publication April 4, 2006

\title{
(In)Definiteness, Polarity, and the Role of wh-morphology in Free Choice
}

\author{
ANASTASIA GIANNAKIDOU \\ University of Chicago \\ LISA LAI-SHEN CHENG \\ Leiden University
}

\begin{abstract}
In this paper we reconsider the issue of free choice and the role of the whmorphology employed in it. We show that the property of being an interrogative whword alone is not sufficient for free choice, and that semantic and sometimes even morphological definiteness is a pre-requisite for some free choice items (FCIs) in certain languages, e.g. in Greek and Mandarin Chinese. We propose a theory that explains the polarity behaviour of FCIs cross-linguistically, and allows indefinite (Giannakidou 2001) as well as definite-like FCIs. The difference is manifested as a lexical distinction in English between any (indefinite) and wh-ever (definite); in Greek it appears as a choice between a FCI nominal modifier (taking an NP argument), which illustrates the indefinite option, and a FC free relative illustrating the definite one. We provide a compositional analysis of Greek FCIs in both incarnations, and derive in a parallel manner the Chinese FCIs. Here the definite versus indefinite alternation is manifested in the presence or absence of $d \bar{o} u$, which we take to express the maximality operator. It is thus shown that what we see in the morphology of FCIs in Greek is reflected in syntax in Chinese.

Our analysis has important consequences for the class of so-called whindeterminates. In the context of current proposals, free choiceness is taken to come routinely from interrogative semantics, and wh-indeterminates are treated as question words which can freely become FCIs (Kratzer and Shimoyama 2002). Our results from Mandarin and Greek emphasize that wh-indeterminates do not form a uniform class in this respect, and that interrogative semantics alone cannot predict either sensitivity of free choice to definiteness, or the polarity behaviour of FCIs.
\end{abstract}

\section{INTRODUCTION}

It is often observed that languages exploit wh-morphology for the formation of free choice paradigms. For example, wh-phrases, augmented by some kind of modal marking or focus additive particle 
(meaning too, and, even or) appear as free choice items (FCIs) in languages as typologically diverse as Greek, Japanese, and Hindi:

(1) a. Greek

opjos-dhipote, lit. who-modal marker (Giannakidou 1998, 2001)

b. Catalan

qual-sevol, lit. who-modal marker

c. Spanish

qual-quiera, lit. who-modal marker

(Quer 1998)

d. Dutch

wie dan ook, lit. who-then-too

(Quer 1999)

e. Korean

nwukwu-na, lit. Who-or

nwukwu-to, lit. who-and

f. Japanese

dare-demo lit. who-even

g. Hindi

jo-bhii lit. lit. which-even

(Rullmann 1996)

(Lee 1997; Gill et al. 2002)

(Nishigauchi 1986)

(Dayal 1995; Lahiri 1998)

English is part of this paradigm too, as can be seen in the use of whever, which has a reading parallel to the so-called free choice any:

(2) a. I will order whatever is recommended by the chef.

b. I will order anything that is recommended by the chef.

Horn (2000a) analyses wh-ever items as FCIs. Syntactically, any and whever differ in that wh-ever requires a clausal complement and always forms a free relative, whereas any is used as a DP constituent, a difference that will prove central to the analysis we will propose in this paper.

Given the paradigm above, the first question we are going to ask is whether the property of being an interrogative wh-word alone is a sufficient condition for free choiceness. There are two sets of facts suggesting that the answer to this question must be negative. The first observation has to do with the formation of the Greek FCI paradigm that we see below:

[o-pjos]-dhipote

[o-ti]-dhipote

[o-pote]-dhipote

[o-pu]-dhipote the-who/which-modal marker (Greek)

the-what-modal marker

the-when-modal marker

the-where-modal marker

(4) *pjos-dhipote; *ti-dhipote; *pote-dhipote; ${ }^{*}$ pu-dhipote

The FCI form consists, on the one hand, of a wh-phrase (or determiner) preceded, crucially, by what appears to be the definite article $o$, and the modal free choice marker dhipote 'ever', on the other. 
The sequence $[o+$ interrogative $w h$-word] is used in forming free relatives in Greek, and is distinct from the interrogative wh-word, which is unable to combine on its own with the free choice marker to form FCIs as we see in (4). The determiner $o$ in the free-relative-wh appears as a bound morpheme and remains invariant in terms of gender number and case (contrary to what is normally the case with Greek determiners, which inflect fully for $\phi$ features and case), suggesting that what is used for FCI formation is actually not the definite determiner itself, but the definiteness core. From the contrast between (3) and (4), it is clear that the wh-component in the FCI, e.g. opjos, oti, opote, etc., is a definite wh-form, and not just a mere question word. This runs counter to the idea that plain interrogative wh-words are a sufficient source for free choice (Kratzer and Shimoyama 2002).

The second piece of evidence supporting the role of some form of definiteness comes from Mandarin Chinese, a language with so-called wh-indeterminates. Mandarin employs only a single wh-paradigm (Cheng 1991). However, bare wh-phrases do not exhibit FCIinterpretations routinely, or polarity FCI behaviour; it is only the D-linked wh-phrase nă-CL 'which' that does.
a. Shéi dōu jìnlái-le. who dou enter-PERF 'Everyone entered.'
b. *Nă-ge xuéshēng dōu jìnlái-le. which-CL student dōu enter-PERF 'Every/any student entered.'
c. Nă-ge xuéshēng dōu kĕy̆ jìnlái. which-CL student dōu can enter 'Any student can enter.'

$N a \breve{a}$ 'which' is morphologically identical to the demonstrative nà 'that', suggesting a parallel with the Greek definite marker $o$ we just noted. ${ }^{1}$ Example (5) shows that a bare wh-phrase such as shéi 'who' is less restricted in its distribution, in comparison to nă-ge xuéshēng 'which student', which exhibits the limited distribution observed for polarity FCIs in Greek, Spanish, and Catalan (Giannakidou 1997, 1998, 2001; Quer 1998, 1999). Specifically, nă-CL NP is unacceptable in episodic contexts (5b) (with the verb being marked by $-l e$, the perfective marker). This observation is further supported by the cases below,

\footnotetext{
${ }^{1} \mathrm{Na}$ 'which' and $n a ̀$ 'that' in Mandarin Chinese differ in tone; the former has the third tone (falling-rising).
} 
where the FC reading of $n \breve{a}$-CL NP is unacceptable in episodic questions and with negation:
a. ${ }^{*} \mathrm{Ta}$ măi-le
nă-bĕn
shū
ma?
(Mandarin Chinese)
he buy-PERF which-CL book $\mathrm{Y} / \mathrm{N}$
Intended: 'Did he buy any book?'
b. Tā méiyŏu măi nă-bĕn shū?
he not-have buy which-CL book
'Which book did he not buy?'
Not: 'He didn't buy any book.'

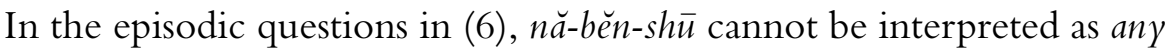
book and contributes only the interrogative wh-meaning (which is incompatible with the yes/no question particle $m a$ in (6a)). Hence năCL NPs seem to be true polarity FCIs, amenable to the intensional analysis of Greek, Spanish and Catalan FCIs, that we will propose in section 5. Again, the fact that there is a split in the $w h$-paradigm-only the which phrase becomes an FCI-is not compatible with the idea that the source of free choiceness is simply interrogative semantics; instead, we must say something specific about the D-linked nă 'which'. It will turn out, in section 5 , that $n \breve{a}-\mathrm{CL}-\mathrm{FCIs}$ and the Greek FCI have very similar compositions, which explains their polarity behaviour.

Our primary goal in this paper is to address the question of what makes wh-phrases suitable candidates for FCIs, and what exactly the conditions are on the candidacy. We will propose a variable binding semantics in the Heim-Kamp sense, augmented with the widely accepted implementation of definiteness for free relatives (Jacobson 1995). We propose that there are two kinds of FCIs: indefinite as well as definite ones, depending on whether or not there is an active definiteness function, i.e. an expression that contributes maximality operating on top of the wh-core of the FCI. We show that, typically, the difference is reflected syntactically as one between FCI-nominals, i.e. FCIs like any that take NP arguments, which are indefinite, and FCI free relatives (i.e. FCIs taking CP arguments like English wh-ever), for which a definite analysis is plausible. For the Greek item opjosdhipote both analyses will be appropriate depending on whether the FCI modifies an NP or a CP. For Mandarin năa-CL NP, the presence of $d \bar{o} u$, which we analyse as the iota operator equivalent to Greek $o$, renders $n \breve{a}$-CL semantically a definite regardless of the type of argument it selects. However, the definite versus indefinite distinction is still found in Chinese with $n \breve{a}$-CL NP since it is possible to have năa-CL NP with $d \bar{o} u$ and also nă-CL NP without $d \bar{o} u$. The former is akin to a semantic definite and the latter to an indefinite, as can be seen from 
the examples which show that the presence of $d \bar{o} u$ leads to ruling out the empty set (section 5).

The structure of the paper is as follows. In section 2, we present the basic properties of free choice that we consider in this paper: antiepisodicity, polarity, and variation. In section 3 we outline the background analysis that we are assuming (Giannakidou 2001), and offer a novel compositional analysis of the class of FCIs that operate on NP arguments and are indefinite. In section 4 we discuss the precise nature of the definiteness of FCIs with clausal arguments. We address the contrast between plain and -ever structures, as well as any versus whever in English, and present evidence supporting the definiteness analysis of free relatives and wh-ever forms. In this connection, we also consider certain arguments that appear to question it (from Grosu 1996, Larson 1999, and Horn 2000a). It is illustrated that these arguments do not really undermine the idea that some form of definiteness is involved in the free relative, but rather make clear the need to distinguish between morphological definiteness and semantic definiteness which we take to be essentially maximality. In section 5 we focus on the Mandarin data. It will be proposed that $d \bar{o} u$ expresses the iota-as-maximality operator (rather than a universal or distributive operator as was previously assumed), and speculate that the use of additive particles in other languages (Dutch, Japanese, Korean, Hindi) serves the same purpose (see Tancredi and Yamashina 2004 for an analysis of Japanese mo consistent with this idea). We further argue that $n \breve{a}$-CL NP is intensionalized by means of a (possibly covert) wúlùn, which counts as the Mandarin equivalent to the Greek dhipote. We close with the implications and predictions of our analysis for whindeterminates, as well as the general theory of polarity.

\section{CORE PROPERTIES OF FREE CHOICE: ANTI-EPISODITY, POLARITY AND Q-VARIABILITY}

There are two fundamental properties of FCIs cross-linguistically. The first has to do with their distribution: many FCIs exhibit limited distribution characteristic of polarity items (PIs; Giannakidou 1998, 2001; Quer 1998, 1999). The second property is that FCIs exhibit the quantificational variability characteristic of indefinites (Horn 2000a; Giannakidou 2001; Dayal 1995). At the same time FCIs retain a universal-like, scalar dimension in their meaning which has been characterized in various works as widening (Kadmon and Landman 1993), concessiveness (Lee 1997), or arbitrariness (Tovena and Jayez 1997). The same intuition of domain extension is present also in Lee 
and Horn's (1994) analysis of any as containing a silent even (but see Lahiri 1998 for a criticism of this idea). This dimension of domain extension is often responsible for the concessive flavour of statements with FCIs (see especially Lee 1997), and sometimes materializes in the form of actual concessive markers such as the particles ke na and ke an in Greek, which may appear with FCI-free relatives (see discussion in section 4.3). Scalarity alone, however, does not seem to affect the grammatical characteristics of FC that we identify here, i.e. it cannot explain the polarity behaviour of FCIs (for an attempt, see Krifka 1995), as it cannot rule out FCI nominals in the core ungrammatical cases of positive sentences (a point argued for in detail in Giannakidou 2001). But it certainly is a component of FC meaning that we want to capture in the intensional analysis we will put forth.

To avoid repeating discussions that are made in the literature already, we describe the polarity and quantificational variability of FCIs only briefly below (for more details see Giannakidou 1998, 2001; Quer 1999; Horn 2000a, 2000b). The properties we are describing apply to what we called FCI-nominals, i.e. FCIs that take NP arguments, or appear as independent QP constituents themselves, which are mainly the FCIs studied in the works mentioned above.

\subsection{Anti-episodicity and polarity}

The polarity property of FCIs is shown below: FCIs are unacceptable in episodic contexts, positive and negative alike; FCIs in Spanish, Catalan and Greek are typical examples:
(7)
a. *Idha
opjondhipote. saw.perf.1sg FCI person
'*I saw anybody.'
b. *Dhen idha not saw.perf.1sg FCI person
(Greek; Giannakidou 2001)
Intended: 'I didn't see anybody'.

(8) *(Non) Expulsaron del partido a cualquier disidente. not expel.3pl from-the party ACC FCI dissident Intended: '* They expelled any dissident from the party.' Intended: 'They didn't expel any dissident from the party.'

(Spanish; Quer 1999)

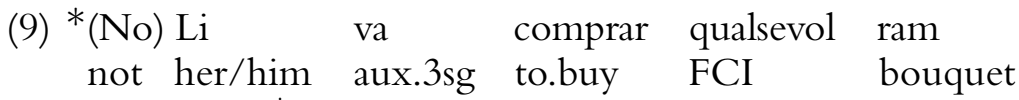

Intended: '*S/he bought him/her any bouquet.'

Intended: 'S/he didn't buy him/her any bouquet.'

(Catalan; Quer 1998) 
The sentences above are episodic. A sentence is episodic when it is about exactly one event that happens at a particular time (Giannakidou 1997, 1998, 2001; Krifka et al 1995):

(10) a. $\exists$ !e $\phi(e)$

b. Episodicity understood here: $\exists$ !e $\exists$ !t $[\phi(e) \wedge \mathrm{e} \subseteq \mathrm{t}]$

(Giannakidou 2001: 662, (5))

Episodic sentences involve (in a particular world) just one event that happens at a particular point in time, an interpretation signalled by perfective aspect in the Greek examples (recall also the perfective Le in the Chinese). ${ }^{2}$ They are in this sense event-specific. FCIs are, apparently, incompatible with this kind of specificity (and require variation for reasons that will be made precise later). Further, the fact that FCIs are excluded from positive and negative episodic sentences alike suggests that it is not non-veridicality per se that FCIs are sensitive to but antiepisodicity (Giannakidou 1997, 1998, 2001). ${ }^{3}$ Finally, let us also note that the anti-episodicity observation holds for FCI-nominals but not for FCIs with clausal structure, which are fine in episodic sentences and have non-polarity status (a point to which we return in section 4):

(11) a. ${ }^{*}$ Last night at the party, Bill talked to any woman.

b. Last night at the party, Bill talked to any woman who seemed interested.

${ }^{2}$ The observation about anti-episodicity is consistent with Jayez and Tovena's (J\&T 2005) nonindividuation constraint which requires that "the information conveyed by the sentence [with the FCI, addition G\&C] should not be reducible to a "referential" situation, i.e. a situation in which particular individuals in the current world satisfy the sentence.' (J\&T 2005: 2) This constraint is stipulated composition-externally as a filter for ruling out improper cases of any and FCIs, but sensitivity to episodicity in Giannakidou (2001) is derived as a result of a lexical semantic property of FCIs. It is this latter line of reasoning we will build on here, as it presents a simpler account where (limited) distribution is derived without stipulating composition external principles.

${ }^{3}$ Very occasionally, episodicity can be overridden with negation in combination with deverbal predicates, like (i):

(i) ?O proedros dhen proxorise se opjadhipote diapragmatefsi.

the president not proceeded.perf.3sg in FC negotiation

'The president didn't proceed with any negotiations.'

Such sentences, however, are never impeccable. Crucially, the complement NP of the FC determiner must be deverbal (see Vlachou in prep. for more extensive corpus data supporting this). An obvious hypothesis for the improvement may be that the deverbal NP contains a clausal-like structure thus rendering these cases subtrigging (the term from Le Grand 1975); we return to this phenomenon in sections 4.3 and 4.4. However, we must note that improvement is impossible with de-verbal predicates in the absence of negation. The positive version of the sentence above, (ii), remains bad:

(ii) $* \mathrm{O}$ proedros proxorise se opjadhipote diapragmatefsi.

the president proceeded.perf.3sg in FC negotiation

??The president proceeded with any negotiations.

So the question as to what is going on with examples like (i) remains open, and the fact that without negation anti-episodicity wins suggests that invoking clausal structure for (i) is probably not the only factor responsible for improvement. 
For FCI nominals, anti-episodicity seems to be at work also in episodic questions (again, with perfective aspect):

*Su sistisan opjondhipote thavmasti? (Greek)
you introduced.perf.3pl FC admirer
Intended: 'Did they introduce any admirer to you?'
*Et van presentar qualsevol admirador?
to-you aux.3pl introduced FC admirer
Intended: 'Did they introduce any admirer to you?'

(Catalan; Quer 1998: 220)
4 ${ }^{*} \mathrm{Te}$ presentó a cualquier admirador? (Spanish) you introduced.3pl ACC FC admirer 'Did they introduce any admirer to you?'

Notice also that ${ }^{*}$ Did they introduce almost any admirer to you? is unacceptable, suggesting that the FCI interpretation is not available in an episodic question for any either since almost is typically taken as a diagnosic for FC any (Davison 1980). (Being aware of the problems with the precise workings of almost, noted especially by Lee and Horn 1994, we use the appearance of almost only as a descriptive diagnostic here.)

The FCI nă-CL NP in Mandarin that we identified earlier has the same sensitivity to anti-episodicity, as we noted already. We repeat the relevant examples below: ${ }^{4}$
a. ${ }^{*}$ Tā măi-le nă-běn shū ma? (Mandarin Chinese) he buy-PERF which-CL book Y/N Q-marker Intended: 'Did he buy any book?'
b. Tā méiyŏu măi nă-běn shū he not-have buy which-CL book. 'Which book did he not buy?' Not: 'He didn't buy any book.'

Nă-bèn-sh $\bar{u}$ 'which book' is unacceptable in an episodic question containing $m a$, the question marker in (15a); not even the question

\footnotetext{
${ }^{4}$ The sentence in (15a) becomes better if we use -guo 'experiential aspect' instead of -le, which indicates the perfective aspect. Note that with $-g u o$, there is no limitation to one event, as in (i):

(i) Tā qù guò rìběn

he go EXP Japan

'He has been to Japan.'
}

This sentence is compatible with the fact that he has been to Japan many times-recall our earlier discussion of episodicity. 
meaning 'which book' is available, since this is a yes/no question. Likewise in (15b), and the example below:

(16) *Tāmén yŏu-méi-yŏu jièshào nă-ge chóngbàizhě gěi nǐ. they have-not-have introduce which-CL admirer give you Intended: 'Did they introduce any admirer to you?'

This sentence is a neutral yes-no question with the A-not-A form. Again, just as in (15a), since the non-interrogative (FC) reading of $n \breve{a}$-CL NP 'which NP' is not available (due to episodicity), the sentence becomes ungrammatical because the wh-interrogative cannot appear within a yes-no question. Hence, $n \breve{a}$-CL NP behaves like a polarity FCI.

FCIs typically appear in sentences that involve quantificational (Q-) structures, i.e. with modal, generic, habitual, and intensional Qoperators, in subjunctive complements of volitional and other directive propositional attitudes, in imperatives, and with Q-adverbs of various kinds (for an extensive illustration see Giannakidou 2001, Quer 1998, 1999 and Table 1; earlier discussion also in Bosque 1996). We present here the summary of the relevant data in Table 1 by comparing FCIs to any, and the class labelled in Table 1 as APIs. API stands for 'affective PI', following Giannakidou (1998, 2001): APIs correspond to what is traditionally, but quite inaccurately, known as 'negative' PIs of the weaker kind, i.e. NPIs that appear with negation as well as a wide variety of non-veridical environments (including downward entailing, and nonmonotone or upward entailing ones such as questions, non-monotone

Table 1 (Partial) contrastive distribution of any, FCIs and APIs.

\begin{tabular}{lccc}
\hline Environments & Any & FCIs & APIs \\
\hline 1. Episodic negation & OK & $*$ & OK \\
2. Episodic questions & OK & $*$ & OK \\
3. Conditionals & OK & OK & OK \\
4. Restriction of universal & OK & OK & OK \\
5. Future particle/will & OK & OK & OK \\
6. Modal verbs & OK & OK & OK \\
7. Directive intensional verbs & OK & OK & OK \\
8. Imperatives & OK & OK & OK \\
9. Habituals & OK & OK & OK \\
10. Stative verbs & OK & OK & $*$ \\
11. Generics & OK & OK & $*$ \\
12. Only & OK & $*$ & $*$ \\
13. Emotive factive verbs & OK & $*$ & $*$ \\
14. Affirmative episodic sentences & $*$ & $*$ & $*$ \\
15. Epistemic intensional verbs & $*$ & $*$ & $*$ \\
\hline
\end{tabular}


quantifiers, modal contexts and propositional attitudes; see Giannakidou 1998, 1999 for extensive discussion).

The generalization seems to be that FCIs are unacceptable in veridical and episodic contexts (bottom four rows), but fine in contexts involving implicit or explicit quantification over alternatives (modal, generic, habitual, individual level predicates, and the like). Any, on the other hand, exhibits a distribution freer than both FCIs and APIs, and therefore is fine in episodic contexts, and even in some veridical ones such as, for example, with emotive factive verbs and only.

Some illustrating data are given below. As an example of API we use the Greek form kanenan, which is interpreted as an existential indefinite quantifier without a free choice, scalar, or universal-like flavour (unlike FCIs). The API existential is always a non-specific, non-referential indefinite, leading Giannakidou (1998) to define it as dependent in that it cannot introduce a discourse referent in the actual world (or current file in Heim's 1982 sense), like regular indefinites can. To indicate the difference between the FCI and the non-FCI existential API, in certain clear cases, we translate 'kanenan' as someone or other:

Protasis of conditionals

(17) An kimithis me \{opjondhipote/kanenan\} tha se skotoso. if sleep.2sg with FCI-person/API-person FUT you kill.1sg 'If you sleep with anybody, I'll kill you.'

Directive intensional verbs (selecting subjunctive)

(18)

I Ariadne epemine na afisoume
the Ariadne insisted.3sg subj let.1pl
\{opjondhipote/kanenan\} na perasi mesa.
FCI-person/API-person subj come.3sg in
'Ariadne insisted that we allow anyone in.'
With kanenan: 'Ariadne insisted that we allow someone or other to
come in.'

Modal verbs

(19) Bori na anapse \{opjosdhipote/kanenas\} to fos can.3sg subj lit.3sg FCI-person/API-person the light 'Anyone may have turned on the light.'

With kanenas: 'Someone or other must have turned on the light.' (Notice the need to change to epistemic must in the case of someone or other.)

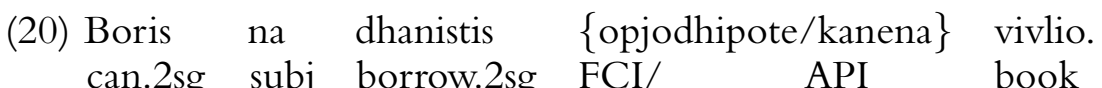

can.2sg subj borrow.2sg FCI/ API book


'You may borrow any book.'

With kanena vivlio: 'You may borrow some book or other.'

Imperatives

(21) Dhialekse \{opjodhipote/kanena\} vivlio. choose.2sg FCI/ API book

'Choose any book.'

With kanena vivlio: 'Choose some book or other.'

\section{Habituals}

(22) Stis sigentrosis, i Ariadne sinithos milouse me at-the meetings, the Ariadne usually talked.imperf.3sg with \{opjondhipote/kanena\} fititi.

FCI/ API student

'At the meetings, Ariadne usually talked to any student'.

With kanena: 'At the meetings, Ariadne usually talked to some student or other.'

An interesting question arising with this preliminary contrastive data is whether the API can indeed be represented as containing a covert marker like or other, an idea that would be consistent with its nonspecificity and narrow scope behaviour. A related task would be to identify the precise contribution of English or other in this structure. Crucially, someone or other has a flavour of epistemic non-specificity (or indifference) distinct from free choice: the statements with some or other convey no scalarity, or the universal-like reading characteristic of FCIs. We will not consider this contrast further, since our focus is on the FCI, but the fact that the use of a disjunctive expression or other does not yield free choiceness is worth noting, especially when we try to link free choiceness to disjunction (Zimmerman 2000; Aloni 2003).

As noted in Table 1, FCIs are unacceptable in certain cases where any is OK, e.g. with negation and episodic questions (recall the examples in the introduction). Here we add factive verbs and only:

$$
\begin{aligned}
& \text { *Monon i Theodora idhe \{opjondhipote/kanenan\} fititi. } \\
& \text { only the Thedora saw.3sg FCI/ API student } \\
& \text { 'Only Theodora saw any students.' }
\end{aligned}
$$

(24) a. ${ }^{*}$ Ekplisome pu exi \{opjondhipote/kanenan\} filo. be-surprised.1sg that has FCI/ API friend 'I'm surprised she has any friends.'

b. *Xerome pu exi \{opjondhipote/kanenan\} filo. be-glad.1sg that has FCI/ API friend '*I'm glad she has any friends.' 
FCIs and APIs thus differ from any which appears with only, and in the complement of a factive emotive verb, as we see. Again, what drives the particular distributional differences between any and the respective Greek items is worth discussing, but doing so here would lead us far afield (see Giannakidou 1998, 2001, section 5 for specific suggestions; also Giannakidou 2006 for an updated view). We simply note here that Greek FCIs behave on a par with APIs in this respect, thus supporting their polarity status.

Regarding FCIs, in order to explain their distribution, Giannakidou proposes an analysis of FCIs as intensional expressions containing a world variable that must be bound by some Q-operator; in an extensional context (and episodic contexts are such) there is no such operator, the world variable remains unbound, and the FCIs become ungrammatical. We come back to this discussion in section 3 .

\subsection{Q-structures and quantificational variability}

The second typical property of FCIs is their universal-like interpretation-a property that prompted analyses of FCIs as universal quantifiers (FCI any in Quine 1960; Horn 1972: chapter 3; Dayal 1998, 2004; Sæbø 2001):

(25) Opjosdhipote fititis bori na lisi afto to provlima. FCI- student can subj solve.3sg this the problem 'Any student can solve this problem.'

However, Vendler (1962) already noted that we need a subtler account of the alleged universal nature of free choice any; and recent cross-linguistic research specifically on wh-based FCIs (lexically distinct from APIs and morphological universals, like in Greek and Chinese) presents compelling evidence that these are not universal quantifiersFCIs are interpreted existentially, e.g. with modal verbs, in conditionals, and imperatives (see Horn 2000b; Giannakidou 2001: 685-703):

(26) I

the

opjondhipote

FCI epitropi committe ipopsifio.

'The committee can offer this job to any candidate.' $\neq$ 'The committee can offer this job to every candidate.'

(27) If you sleep with anybody I'll kill you.

(Uttered by a jealous husband, for whom just sleeping with one guy will be reason enough to proceed with the cruel act.) 
(28) Press any key to continue.

(As a command to resume function.)

Furthermore, FCIs occur with Q-adverbs yielding statements that are reminiscent of construals with indefinites whose variable is bound by the Q-adverb (see Dayal 1995; Giannakidou 2001: 701-703, 715-717 from which the examples below are taken):

(29) a. Sinithos dhiavaze i Ariadne opjodhipote vivlio me usually read.imperf. the Ariadne FCI book with megali prosoxi.

great attention

'Ariadne usually read any book very carefully.'

b. USUALLYs, $\mathrm{x}$ [book $(\mathrm{x}, \mathrm{s}) \wedge \operatorname{read}$ (Ariadne, $\mathrm{x}, \mathrm{s})$; read-carefully (Ariadne, $\mathrm{x}, \mathrm{s})$ ]

(30) a. Spania dhiavaze i Ariadne opjodhipohte vivlio me rarely read.imperf. the Ariadne FCI book with megali prosoxi.

great attention

'Rarely did Ariadne read any book very carefully.'

b. RARELYs,x [book $(\mathrm{x}, \mathrm{s}) \wedge$ read (Ariadne, $\mathrm{x}, \mathrm{s})$; read-carefully (Ariadne, $\mathrm{x}, \mathrm{s}$ )]

These are habitual sentences with imperfective aspect in Greek. In (29), Ariadne read most books with great attention, but in (30) she read only few books with such attention, depending on the choice of adverb. Giannakidou (2001: 715-717) offers extensive discussion, that we will not repeat here, of Q-adverbs and FCIs contrasts in this context with universal quantifiers. The observed variability of FCIs and their striking similarity with indefinites prompted analyses of FCIs as indefinites (in the sense of Heim 1982; Kamp 1981), bound by universal and other quantifiers (for variants of this idea see Bolinger 1977 and more recently: Haspelmath 1997; Kadmon and Landman 1993; Lee and Horn 1994; Dayal 1995; Quer 1998; Giannakidou 1998, 2001; Horn 2000a, 2000b, 2005). A welcome consequence of such an analysis is that it provides a way to capture the fact that FCIs occur only if a Q-operator is present, and that their quantificational force is parasitic on that of the $\mathrm{Q}$-operator.

It is not necessary for our purposes here to review the arguments for indefiniteness in more detail since most of the points are made at length elsewhere (see especially Horn 2000b, 2005 and Giannakidou 2001). So we take the indefinite analysis of FCIs as our starting point: FCIs are indefinites. But, unlike regular indefinites, FCIs have limited distribution, which means that they must be different somehow. In what sense are they different? 


\section{FCIs AS INDEFINITES: INTENSIONALITY AND EXHAUSTIVE VARIATION}

In this section we consider the analysis of FCI nominals, i.e. FCIs when they are used independently as QPs, or when they are used as determiners and take an NP argument. Not all FCIs can take up this function, e.g. wh-ever cannot:

(31) a. \{Anybody/Any student $\}$ can solve this problem.

b. $\{*$ Whoever $/ *$ Whichever student $\}$ can solve this problem.

Wh-ever requires a $\mathrm{CP}$ argument thus always forming a free relative (FR) - though there are some limited exceptions to this generalization that we discuss more in footnotes 5 and 8 . We will call this construal free choice free relative (FC-FR). The analysis we use as background here (Giannakidou 2001) did not consider FC-FRs and offered an account of FCI nominals only. We start by fleshing out, and modifying, that account. In section 4 we extend this analysis to FC-FRs, and discuss how the intensionality of FC interacts with the syntactic structure of FRs in producing FCIs which end up definite, and not polarity sensitive. From this analysis, a simpler account of sub-trigging will emerge in section 4.4.

\subsection{Intensionality}

Giannakidou (2001) proposes that FCI nominals are intensional indefinites: they contain a world variable that is dependent and must be bound by some operator external to the FCI but indeed available in the sentence of occurrence. This accounts immediately for the need to be in a quantified sentence and the anti-episodicity effect. Free choice intensionality in Greek is designated by -dhipote. In this analysis, the FC determiner is treated as a property modifier which, when applied to the NP denotation, returns an intensionalized property as its output.

$$
\llbracket \mathrm{DET}_{\mathrm{FC}} \rrbracket=\lambda P_{<s, e t>} . \lambda w \lambda x[P(x)(w)]
$$

So, the FC-determiner takes a property $P$ as input and gives back its Montagovian intension, i.e. a function from worlds $w$ to sets of individuals $\left({ }^{\wedge} P\right)$. Note that the NP argument contains already an open $s$ position (in line with recent observations in the literature, e.g. about temporal and situational arguments of NPs, see Enç 1991), hence the FC determiner works as an identity function and preserves the intensional type of the NP. In the ordinary case, i.e. with a regular (non-FC) determiner, the $s$ index of the NP argument will be interpreted as a constant, i.e. as referring to the actual world and can 
thus be ignored; the NP will therefore denote a set of actual individuals. This is not an option for the FCI, whose $w$ variable remains dependent in that it is in need of binding, as we elaborate on next. It is in this way that the FC-determiner contrasts with regular determiners, and 'intensionalizes' the NP. In the end, we have a phrase that denotes an NP with two variables instead of one: the regular individual variable, and an additional world variable:

$$
\text { \opjosdhipote fititis }=\lambda w \lambda x \cdot \operatorname{student}(x)(w)
$$

This $w$ variable cannot remain free, but must be bound by an operator that has the ability to bind such variables (a Q-operator, i.e. a generic, habitual, modal, intensional operator). It is in this sense dependent (Giannakidou 2001: 704-705). The presence of a dependent world variable is the defining feature of FCIs - and we propose in section 5 that the Mandarin FCIs contain it too. A different form of dependency will be shown to arise when the $w$ variable remains bound by the $\lambda$ operator, as is the case with definite FCIs in Mandarin and Greek.

Before we proceed, let us note that admitting a dependent variable in need of Q-closure is not at all unconventional. It is widely accepted in the literature that not all variables are alike. This underlies, for example, the very common idea that some variables must be used only if their presuppositions are satisfied, e.g. the variables of definites are distinct in this way, or the variables of 'specific' indefinites (e.g. Farkas 2002; see also discussion of positive polarity items in Giannakidou 2002); recall also Heim's familiarity and novelty conditions on the interpretation of definite and indefinite variables. Likewise, anaphors contain variables dependent on an antecedent for well-formedness. The dependent world variable of FCI nominals of the Greek type can be viewed as anaphoric in this broader sense, and we can posit the dependency as a presupposition if it fits better the more general assumptions that we have in mind.

Because the $w$ variable cannot remain free, FCIs will be wellformed only if there is some Q-operator in the sentence that can bind it. In episodic sentences, FCIs are out because no such operator is present, and $w$ remains unbound. This analysis explains the polarity status and anti-episodicity property of FCI nominals that have the characteristic distribution of the Greek type.

To make the composition explicit we will use another observation showing that an FC-phrase can co-occur with an indefinite determiner (Giannakidou 2001: example (85) repeated below as (34)), in Greek as well as in other languages (e.g. Spanish, see Quer 1999). 


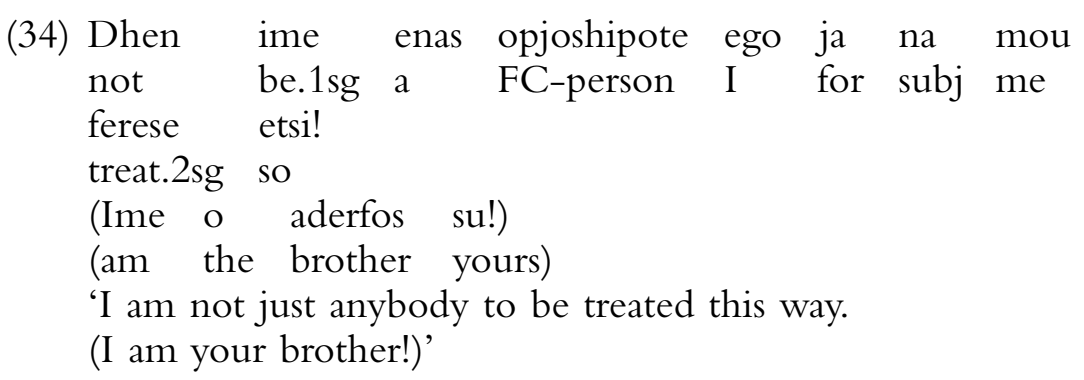

This provides sufficient grounds for assuming that in fact the FCI always contains an indefinite determiner on top of the FCI layer, as indicated in the structure below. The FCI derivation of (enas) opjosdhipote fititis 'any student' then proceeds as indicated:

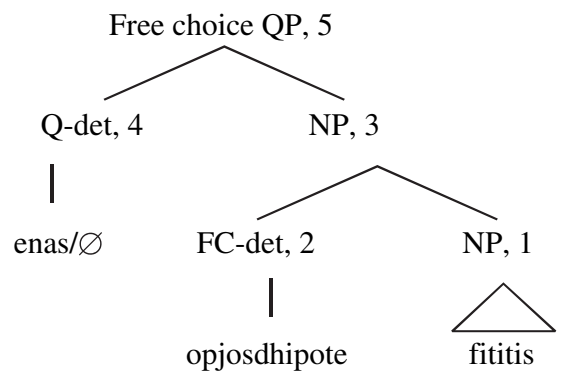

1. $\llbracket$ fitititis $\rrbracket=\lambda w \lambda x$.student $(x)(w)$

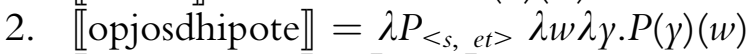

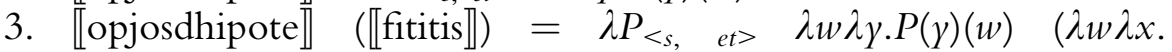
student $(x)(w))=\lambda w \lambda x$.student $(x)(w)$. This is the intension of the predicate 'student'.

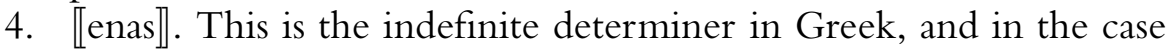
of the FCI nominal it can be overt or covert. We take it that it works like a Heimian indefinite function, i.e. as a function from properties to propositions: it takes the NP property as its input and gives back a sentence with open variable positions - this time with two variables $x$ and $w$ since the input to enas is the intension of the property $\mathrm{P}$.

【enas $\rrbracket=\lambda P_{<s, e t>} P(x)(w)$

After application of the indefinite determiner at the top of the FC phrase, we end up with an open world variable, which is dependent and cannot receive the value of $w_{0}$, the actual world:

5. $\llbracket$ Free choice $\mathrm{QP} \rrbracket=\operatorname{student}(x)(w)$ 
Finally, a comment on the contrast between opjos and opjosdhipote, which will also be helpful in the discussion of the FR paradigm later. As we see in (36b), the Greek bare wh-phrase (opjos i.e., without-dhipote) cannot take an NP argument; it also cannot serve as an independent QP constituent by itself (36c):
(36) a. Opjosdhipote fititis bori na lisi afto to provlima. FCI student can subj solve this the problem 'Whichever student can solve this problem.'
b. 'Opjos fititis bori na lisi afto to provlima.
'Any student can solve this problem.'
c. $\left\{{ }^{*}\right.$ Opjos/Opjosdhipote $\}$ bori na lisi afto to provlima. 'Anyone can solve this problem.'

The fact that the bare wh-form is not allowed as a determiner or quantifier, and, crucially, the fact that the FCI nominal is itself the input to an indefinite determiner, as we have seen, suggest that opjosdhipote, as an NP modifier, is a lexical unit without being semantically or morphologically decomposed in a strict compositional way from all its parts. The effect of this is that the morphological definiteness of $o$ - remains inactive, or, to put it differently, does not contribute definiteness in the semantics, and the unit as a whole behaves as an indefinite. In our discussion of Chinese $n \breve{a}$ in section 5 , a parallel situation will arise, where the D-linked năa-phrase 'whichphrase' will behave like an indefinite in the absence of $\overline{d o} u$. In this case too we will have to say that, though present morphologically, definiteness is actually bleached semantically. ${ }^{5}$

The situation with nominal FCI contrasts with the FC-FR, where opjos as well as opjosdhipote are available, as we see:

a. Opjosdhipote (fititis) irthe sto party efxaristithike. wh+FC-det student came.3sg to-the party was.happy.3sg ' $\{$ Whoever/Whichever student $\}$ came to the party had a great time.'

b. Opjos (fititis) irthe sto party efxaristithike. *' $\{$ Who/Which student $\}$ came to the party had a great time.'

\footnotetext{
${ }^{5}$ Though this may sound like a weakening of our claim for the role of definiteness in deriving FC meanings from wh-morphology, it is worth pointing out that in essence it amounts to saying that, given the presence of morphological definiteness, it is then up to the syntactic structure to determine whether definiteness will be allowed to play a role in the semantics or not. In the case of the free relative, the structure is closed by a definiteness node (following Jacobson), and the result will be a definite FC phrase (as we will see in more detail in section 4); but in the case of the FCI nominal, we have closure under an indefinite determiner, which blocks, or cancels out definiteness, in either case preventing it from making a contribution in the semantics.
} 
Here it can indeed be argued that the FC-wh phrase is derived compositionally by application of -dhipote to the meaning of the bare wh-phrase. Notice, also the contrast with the English FR: only the wh-ever paradigm is allowed. ${ }^{6}$ We come back to this fact, and the consequences it has for the English FC-FR in section 4, after the analysis of the Greek FR is made clear.

\subsection{Exhaustive variation}

Apart from intensionality, another important lexical semantic feature of FCIs is exhaustive variation: the FCI variable must be assigned distinct values in each world or situation we consider, and we consider all (relevant) possible worlds. This property derives the quasi-universal effect of FCIs, and Giannakidou (2001) proposes to capture it in the notion of an i(dentity)-alternative (following Dayal 1997):

\section{(38) i-alternatives}

A world $w_{1}$ is an i-alternative wrt $\alpha$ iff there exists some $w_{2}$ such that $\llbracket \alpha \rrbracket^{w 1} \neq \llbracket \alpha \rrbracket^{w 2}$ and for all $\beta \neq \alpha: \llbracket \beta \rrbracket^{w 1}=\llbracket \beta \rrbracket^{w 2}$

Two i-alternatives are worlds $w_{1}$ and $w_{2}$ agreeing on everything but the value assigned to the FCI $\alpha$, and we will incorporate this in our definition below (adopted from Giannakidou 2001). Importantly, what is significant for capturing the variation of FCIs is not so much the characterization of worlds as i-alternatives, but rather the availability of possible worlds in the first place. Such worlds will be, naturally, the worlds that the $\mathrm{Q}$ operator quantifies over, and some of these worlds

\footnotetext{
${ }^{6}$ Plain what FRs present an exception to this: I ate what he cooked and I ate whatever he cooked. We may also find occasional cases of plain who and where, as a reviewer points out, such as I like who(ever) she likes, and I'll go where(ever) you go. However, such cases seem to form a distinct class in at least two ways: they involve identical VPs in the main clause and the FR, and are sensitive to anti-episodicity. If these conditions do not hold, bare who becomes ill-formed:

(i) a. */?? (Last night at the party) I talked to who you met at the store.

b. */?? (Last night at the party) I talked to who you talked to.

Additionally, bare wh-FR other than what is not allowed in the subject position:

(ii) *Who you talked to yesterday was a great guy.

It makes sense, then, to treat the occasional instance of bare $w h$ - in FR as exceptional, on a par with what, which is known to be different for other reasons too, and we will not take them to threaten our generalization here. Moreover, the fact that the attested examples of bare $w h$-phrases mostly concern object positions seem to suggest that these $w h$-clauses may be genuine clausal objects rather than FRs, an ambiguity created by the fact that there is no morphological marking specific to the FR in English (unlike in Greek).
} 
can be much less stereotypical, i.e. less similar, to the actual one, an assumption necessary to capture the intuition of domain extension and scalarity that we get with free choice. It is also important to emphasize that the existence of possible worlds for variation is a condition on the context of the FCI (i.e. a presupposition), and that the FCI nominal itself cannot introduce these alternatives; if it could, it should be able to do so also in an episodic sentence with the result of licensing itself contrary to fact. (38) gives the criterion for what counts as a valid ialternative: only worlds with differing values for the FCI count as ialternatives. Summarizing, then, we have the following semantics for FCIs (Giannakidou 2001: (129)):

\section{(39) Free choice item (= FCI nominal)}

Let $W_{i}$ be a non-empty, non-singleton set of possible worlds. A sentence with a free choice item $\llbracket O P \operatorname{DET}_{\mathrm{FC}}(P, Q) \rrbracket$ is true in $W_{0}$ with respect to $W_{i}$ iff: (where $O P$ is a nonveridical operator; $P$ is the descriptive content of the FC-phrase; $Q$ is the nucleus of the tripartite structure; $W_{0}$ is the actual world):

a. Presupposition: $\forall w_{1}, w_{2} \in W_{i}: \llbracket \alpha \rrbracket^{w 1} \neq \llbracket \alpha \rrbracket^{w 2}$, where $\alpha$ is the free choice phrase.

b. Assertion: $\llbracket O P w, x[P(x, w) ; Q(x, w)] \rrbracket=1$ where $x, w$ are the variables contributed by $\alpha$.

We see that the requirement of exhaustive variation is a universal clause posited as a presupposition of FCIs: the context must provide alternative worlds (i.e. the existential commitment statement at the basis of all universals in (39a)), we must consider all alternatives, and since in each alternative we have a different value, we exhaust the possible values for the $\mathrm{FCI}^{7}$ In the assertive component, the FC indefinite is bound by the relevant operator and obtains the quantificational force contributed by that operator. This accounts for the quantificational variability effect, i.e. the shift from existential to universal readings, and the intermediate forces observed with Q-adverbs. We will not go into more detail here-for extensive

\footnotetext{
${ }^{7}$ At this point we may wonder whether the FC definition we are using here may be too intensional (thanks to a reviewer for bringing this up). For instance, a sentence like John can beat any of his students at chess is it about actual students of John, or do we also want to include possible but not actual students of John, as would be implied by (39)? The same question would also arise in the absence of the partitive: John can beat any student at chess. The intuition, we believe, is that such sentences are not only about actual students but also non-actual ones (something close to if some $x$ in a world $w$ is a student (of John), then John can beat $x$ at chess in $w$ ), thus supporting the definition we give here.
} 
discussion of particular examples and subcases see (Giannakidou 2001).

This analysis succeeds in handling a substantial amount of data concerning the distribution and interpretation of FCI nominals. Moreover, it can be made fully compositional, as we illustrated in the previous subsection. However, it does not offer a way to address the difference between FCI-nominals and FC-FRs, and the parallel distinction between any and the wh-ever form in English; nor does it address the related issue of definiteness that we emphasized at the beginning. It is these issues that we take up next.

\section{FREE CHOICE FREE RELATIVES}

In this section we will present an analysis of the class of FCIs that we identify as definite. We will take it that FCIs that occur in free relative structures (FC-FRs) exhibit typically this case —although being an FR is not a necessary condition for being a definite FCI (e.g., the Mandarin $n \breve{a}$-items that we discuss in section 5 are definite even though they are not clausal). In order to account for the semantic difference between FCI-nominals (any, opjsodhipote modifying an NP), which we just analysed as indefinite, and FC-FRs (wh-ever, opjosdhipote selecting a CP complement), which we intend to analyse as definite in a way to be made precise shortly, we need to think a little bit more about their empirical differences.

It will be helpful to look at these differences as they are manifested in the contrast between any and wh-ever in subsection 4.1. After this is done and we establish that a form of semantic definiteness is involved in the FC-FR construal, we turn to the derivation of the plain Greek FR, adopting the analysis of Jacobson 1995 (section 4.2). Then we discuss the impact of FC-dhipote on the FR (section 4.3). Finally, we revisit wh-ever and explain its non-polarity status in the light of the analysis of the Greek data, and the phenomenon of subtrigging (4.4). It will turn out that the wh-ever FR is actually ambiguous between FC and the plain construal, and it is this that allows it to appear in the purely extensional and veridical context of ignorance readings, where the Greek FC-FR, being only free choice, is disallowed.

\subsection{The nature of definiteness in FC free relatives}

First, the defining syntactic difference between a FCI-nominal (any) and a FC-FR with wh-ever is that the latter is always part of an FR 
structure and, unlike any, cannot occur independently or as a nominal modifier: ${ }^{8}$

(40) a. Whoever saw a fly in his soup complained to the manager. b. $*\{$ Whoever/whichever customer $\}$ complained to the manager.

c. $\{$ Anybody/any customer $\}$ can complain to the manager. (with a modal added for well-formedness)

The sentences above show that wh-ever is different from any and the nominal FCI we have been discussing so far, which select NP arguments, or can be used as such. If FCIs selecting NPs are intensional indefinites with the structure we described in (35), then the impossibility of wh-ever to select an NP argument suggests that this analysis cannot be extended to this item. In other words, wh-ever

${ }^{8}$ A reviewer points out that there are indeed some cases where a wh-ever form occurs as an independent nominal in a non-subject position, e.g.:
(i) a. Q: What should I do?
A: \{Whatever / ??Anything
b. You can leave whenever.
c. She complains to the manager about $\{$ whatever/anything .

However, there are reasons not to want to treat these cases of self-standing whatever as part of the regular FC $w h$-ever cases we are talking about here. Note, first, that they have an idiomatic-like interpretation quite different from that of the regular FC-FR. Specifically, self-standing whatever receives only the indiscriminative reading of Horn (2000a), which tends to express only negative evaluation, and lacks the actual free choice reading of the typical FCI which contains also a neutral evaluation. In support of this, notice the contrast in (i)a, where anything is odd as an self-standing answer exactly because it cannot receive in isolation the indiscriminative meaning (which appears typically with just anything).

Second, self-standing wh-ever involves specific wh-forms, e.g. whatever, and to some extent whoever and whenever but not, for example, the wh-ever form as a modifier:

(ii) Give the flowers to \{?whoever/??whichever student $\}$.

Finally, note that, unlike regular wh-ever, which is not triggered and can occur in episodic contexts (i.e. subtrigging that we discuss next in the text), these apparent independent forms are triggered, and cannot be used in an episodic context. Notice the contrast between the good cases above, and the bad episodic ones below, as they differ from regular FC-FRs:

(iii) Q: Who did he talk to at the meeting?

A: *Whoever.

OK. $\{$ Whoever/Anyone who $\}$ was willing to talk to him.

(iv) *She left whenever. OK: She left whenever she was told to.

(v) At the party, Laura gave the flowers to *whoever/OK: whoever she liked.

(vi) * She complained to the manager about whoever/anything (as opposed to the non-episodic (ic)).

In view of this contrast with respect to episodicity, it makes more sense to treat the occasional independent wh-ever not as part of the typical wh-ever that is used in the FR paradigm, but rather as a distinct lexicalization that is an PI itself. Unlike typical FC-FRs, independent PI wh-ever follows the triggering pattern of polarity sensitive FCI nominals, and is ruled out by episodicity. Whether this analysis would necessarily render the independent wh-ever form an indefinite is a question that we will not speculate on here. 
cannot be an intensional indefinite of the Greek type described here. This, of course, squares with the fact that wh-ever does not seem to exhibit polarity behaviour at all-it is good, for example, in positive episodic contexts:

(41) a. Whoever saw a fly in his soup complained to the manager.

b. *Anyone complained to the manager.

c. ${ }^{*}$ Opjosdhipote paraponethike ston diefthindi. (Greek) FCI-person complained.3sg to-the manager

d. Anyone who saw a fly in his soup complained to the manager.

e. [Opjosdhipote idhe miga sti soupa tu] [wh-ever person saw.3sg fly in-the soup his] paraponethike sto diefthindi (Greek) complained.3sg to-the manager

The sentences above are all positive episodic past, hence veridical: anyone and nominal opjosdhipote in $(41 \mathrm{~b}, \mathrm{c})$ are out, as expected because they are PIs (for the reasons we explained in 3.1). Whoever, in contrast, is good in (41a) because it is accompanied by a clausal complement, which enables a subtrigging structure (the term from LeGrand 1975) which is known to 'rescue' FCIs in the otherwise hostile episodic environments; and it is subtrigging that rescues anyone and opjosdhipote in $(41 \mathrm{~d}, \mathrm{e})$ too. Hence whoever selects a sentential complement, giving rise to subtrigging; such an item consequently will not be subject to licensing at all, for reasons that we discuss in section 4.4. The presence of sentential structure in auto-licensed FCIs (Korean, Japanese) seems to be the reason for autolicensing and the absence of polarity behaviour in those paradigms (as suggested also in Gill et al. 2002), but we will not discuss the cross-linguistic extension further in this paper.

So, there seems to be a split between FCIs selecting NP arguments (the ones we have been calling FCI-nominals), on the one hand, and FC-FRs, on the other, crucially in terms of polarity item status. The analysis we have given in section 3 applies to the former but it cannot extend to the later. Furthermore, the fact that wh-ever heads FRs makes the indefinite analysis less plausible, as FRs are more appropriately treated as definites (Jacobson 1995), a position that we adopt in this paper.

A second difference that supports precisely this split between FCI-nominals (indefinites) and FC-FRs (definites) is observed in the 
sentence below, in terms of what appears to be an expectation of existence:

(42) a. If any student calls, I am not here.

b. Whichever student calls, I am not here.

The sentence (42a) with any is a neutral statement expressing my desire not to talk to anybody, and there is no expectation that somebody will actually call. The one with whichever student (42b), on the other hand, seems to favour (but not require) a context where there is indeed an expectation of call; in fact it can (but does not have to) be an instruction to avoid talking to somebody undesirable. This expectation, which seems to not be as strong as a presupposition, makes sense only in the definite analysis of FRs because we tend to exclude the empty set from the plural FR collection we are forming, as we will suggest below. With an indefinite, there is no such inclination, hence the unmarked use of the FCI indefinite in a neutral context.

It is important to emphasize that the expectation of existence that comes with FRs and wh-ever is not as strong as the existential commitment that comes with morphological plural definites. With morphological definites, in English as well as in Greek, the existential commitment appears to be a presupposition (though this must be taken with a grain of salt, see especially the closing discussion in our footnote 9, and our example (45) below), but with FC-FRs, as we noted, it is not. The contrast between morphological definites and FRs is illustrated in the examples below (thanks to an anonymous reviewer); the discrepancy between FRs and morphological definites was noted already in Horn (2000a: 101-102), and earlier in Grosu (1996: 271) where the examples in (44) are taken from:

(43) She may never marry, but

a. whoever she does marry will be Jewish.

(Horn 2000a)

b. anyone she does marry will be Jewish.

c. \#the person she does marry will be Jewish.

(44) a. Any beer there is in the fridge is mine.

b. Whatever beer there is in the fridge is mine.

c. The beer in the fridge is mine. [no existence-neutral reading possible]

These contrasts agree with our position that whatever the existential import of the FC-FR is, it must not be deemed identical to the 
presupposition of a referential definite description. 9 Jacobson herself also notes (1995: 472) that the FR plural is not identical to the morphological plurals in languages with number marking like English (thus also Greek), as in these languages the morphological plural excludes atoms, and probably also the empty set from its domain (though this may not be, strictly speaking, part of its truth conditional meaning). Our intuition that wh-ever seems to favor, but not require, a context (in example (42b)) where there were indeed callers may therefore be taken to indicate that the empty set tends to also be excluded in the case of FR (though atoms, contrary to morphological plurals, are still allowed).

In this connection, notice that not all instances of morphological definites are committed to existence. Morphological definites seem to be stripped off existence in certain usages, as in the example below, where the FR and the morphological definite behave alike:

(45) a. This golden coin belongs to the sailor that sights the White Whale.

b. This golden coin belongs to whichever sailor sights the White Whale.

(Both consistent with a context where White Whale is not sighted.)

Importantly, in this case the definite and the FR are used attributively (Donnellan 1966) rather than referentially, and this appears to have equal impact on both FRs and morphological definites thus supporting their parallel. The fact that FRs express a somewhat looser commitment to existence may suggest that FRs, unlike morphological definites, are used more often attributively than referentially, an expected pattern given the absence of definite morphology (English), or degenerate morphological definiteness (Greek; recall that the

\footnotetext{
${ }^{9}$ Notice, crucially, that universal quantifiers also come with an existence presupposition, or 'commitment' (to use Horn's 1997 terminoloogy), which becomes evident in cases like (i), parallel to the ones discussed in the text:

(i) $\{$ Every/Each $\}$ bottle of beer in the fridge is mine (\#but there is no beer in the fridge).

The requirement for a non-empty restriction is particularly strong for the strongly distributive each (which is characterized, for this reason, as veridical in Giannakidou 1998, 1999), and can occassionally be waived in the case of every (which is characterized as non-veridical), just like it can be waived in the attributive uses of definites mentioned next in the text:
}

(ii) A golden coin will be given to every sailor that helps capture the White Whale.

Similarly, as we shall see, definites are stripped off existence in such cases. FRs, then, seem to be distinct from morphological definites and universals alike with respect to existence. As regards to the differences between universal quantifiers and FRs, we refer to Jacobson (1995: section 1) for a quite extensive discussion. 
definite marker o that appears with the Greek FR is not, as we mentioned at the beginning, the fully inflected definite determiner, but an uninflected form of it.).

Overall, then, our data here indicate that it is important to distinguish morphological definiteness from semantic definiteness. Given that existence can be dispensed with even with morphological definites, as we just noted, the core of semantic definiteness appears to be the formation of a maximal plural entity, and wh-FRs fully meet this condition. In our more detailed analysis below, we identify $o$ as Jacobson's iota type-shifter, and in the context of the more refined observations we make here it is appropriate to understand iota as the maximality operator, rather than the morphological definite article (which in the referential use contributes both maximality and a presupposition of existence). We will not elaborate on the formal differences at this point, and follow Jacobson (1995) in using iota; and our treatment of iota shift should be understood as simply yielding maximality, and not necessarily presupposing existence, just like in Jacobson's analysis.

In the same context, certain other apparent differences between morphological definite descriptions and FC-FRs become better understood (again, thanks to a reviewer for bringing these up). For instance, the latter but not the former are modifiable by almost:

(46) a. Max gave Alice almost \{?whatever/anything\} she asked for.

b. *Max gave Alice almost the things she asked for.

(from Larson 1999: fn. 10)

Here the wh-FR seems to align with any in being compatible with almost whereas the definite the things is pretty bad (see also Horn 2000a for various Googled examples that illustrate the same point). If we assume, following Lee and Horn (1994) among others, that almost modifies high scalar and universal values, the real question posed by these data is why morphological definites are incompatible with it. It is not decisive for our discussion of FC to address this question here, but a plausible hypothesis, simplifying somewhat, would be to say that the high scalar reading needed for almost modification requires a collective reading which the definite cannot get unless, for example, all is used, in which case the definite becomes fine:

(47) Max gave Alice almost all the things she asked for.

This suggests that the morphological plural definite must be 'hopelessly' distributive in the absence of all. Distributivity is generally at odds with almost: it is this property, for instance, that rules out the 
strongly distributive universal each, and renders it different vis-à-vis almost from other universal quantifiers like all or every:

(48) Max gave Alice almost $\left\{{ }^{*}\right.$ each book/every book $\}$ she asked for.

More discussion at this point would lead us too far afield; suffice it to say that almost and the contrast between plural definites and FC-FRs seem to indicate that FC-FRs are not strongly distributive the way morphological plural definites are. But this is not necessarily an argument against them denoting maximal pluralities in the sense we assume here; it is rather another indication that it would be wrong to collapse morphological with semantic definiteness. ${ }^{10}$

Finally, an additional decisive syntactic fact about wh-ever is that, generally, it cannot occur without -ever, in contrast to its Greek counterpart. We repeat below the contrast from 3.1.

a. Opjosdhipote (fititis) irthe sto party efxaristithike. wh+FC-det student came.3sg to-the party was.happy.3sg ' $\{$ Whoever/Whichever student $\}$ came to the party had a great time.'

b. Opjos (fititis) irthe sto party efxaristithike.

'* $\{$ Who/Which student $\}$ came to the party had a great time.'

We see that the FR wh-phrase in Greek can occur with the FCI modifier-dhipote (in which case it is homophonous with the nominal FCI), or without it, in which case it is a plain FR. The difference is meaningful in Greek in a way that we will try to make precise in the next section.

\footnotetext{
${ }^{10}$ A reviewer suggests an additional difference between definites and FC-FRs in that wh-ever is much better at licensing NPIs than definites, which according to the reviewer, 'aren't great' at this job:
}

(i) I'll read $\{$ whatever $/$ any $/ *$ the $\}$ books you've ever asked me to read.

Though in this example the definite is indeed odd with ever, this case is far from illustrating the norm. It has been shown in the literature that definites (mainly plural) are in fact good licensers of NPIs (Giannakidou 1998, 1999: 396-404, where the example below is taken from):

(ii) The students who know anything about the case should speak now.

According to Giannakidou the crucial factor is whether the definite presupposes existence of a nonempty domain (in which case it is used referentially), or not (in which case it is used attribitively, as we just saw). When it is unclear whether the domain is non-empty, i.e. in the attributive use, NPIs will be OK, as in (ii). If the FC-FR turns out to be freer in licensing NPIs, this supports our earlier suggestion that FRs tend to be used attributively more often than morphological definites. And, again, the fact that definites can come with empty domains (as is possible with (ii)), contradicts the view that definites always contribute existence, a fact that actually brings them closer to FRs, hence supporting the parallel we are trying to establish. 
Our proposal in a nutshell is the following. Free choice variables can be definite (denoting maximal plural individuals) or indefinite, depending on whether the FCIs take nominal or CP arguments. The possibility of a definite variable is fully consistent with, and indeed predicted by, the variable approach to FCIs that we adopt here, and our proposal should be seen as a refinement in this direction. Nominal any exhibits the case of an indefinite variable, and wh-ever illustrates the case of a definite FC variable. In a language like Greek, lacking the phonological distinction between a non-wh and wh-FCI, the wh-form employed encompasses both readings, which are however derived in distinct ways. The FCI-nominal is an indefinite, but the FC-FR contains a definiteness function; the difference is shown to have repercussions for their polarity status, as is the case in English (any being a PI, but wh-ever not).

We now start with the derivation of the plain Greek FR adopting the analysis of Jacobson (1995).

\subsection{The derivation of the plain FR in Greek}

The use of the definite marker $o$ and the FR source of the whcomponent of the Greek FCI support the idea that FRs denote (contextually specified) maximal plural entities; see Jacobson (1995), Rullmann (1996), also Dayal (1995) for a similar analysis of Hindi correlatives, including those containing the FC additive marker bhii. In what follows we will use the analysis of the FR as involving an iota function (which was also developed against an earlier universal analysis of FRs) to propose a derivation of the Greek FC-FR, and its Chinese counterpart nă-CL NP in section 5 . The idea that the Jacobson analysis is appropriate for Greek FRs is found already in Alexiadou and Giannakidou 1998 (pace Iatridou and Varlokosta 1998 who claim that Greek FRs are universal quantifiers); and primary support for it comes from the use of the definite $o$ that appears in the Greek FR.

Jacobson argues that FR wh-words in a language without morphological distinctions like English are not born exactly with the same meaning as the similar wh-relative (Jacobson 1995: 467). Following the classical thesis of Cooper (1983), all wh-phrases start out as properties (the wh-core; type et), but according to Jacobson, the FR undergoes type-shifting to a definite meaning. Here is Jacobson's derivation (using upper case variables; Jacobson 1995: 473):

$$
\text { a. } \llbracket \mathrm{what}_{\mathrm{FR}} \rrbracket=\lambda P \lambda X[P(X) \wedge \forall Y(P(Y) \rightarrow Y \leqslant X)]
$$


b. $\llbracket$ what John ordered $\rrbracket=\llbracket$ what $\rrbracket(\llbracket$ John ordered $\rrbracket)=$ $\lambda P \lambda X[P(X) \wedge \forall Y(P(Y) \rightarrow Y \leqslant X)](\lambda x \operatorname{ordered}(j, x))=$ $\lambda X[\operatorname{ordered}(j, X) \wedge \forall Y(\operatorname{ordered}(j, Y) \rightarrow Y \leqslant X)]$

The FR wh-expression characterizes the set of maximal plural entities that John ordered. Plural entity is assumed in the broadest sense, and includes both atomic individuals as well as the null set (Jacobson 1995: 472). So the wh-expression characterizes some subset of $e^{*}$, the set of plural entities (including atoms and the empty set). This means that the FR-wh expression in effect denotes a set which is guaranteed to be a singleton. It then iota type-shifts, quite expectedly, to denote the single individual characterized by the predicate, as shown below (again, from Jacobson 1995: (57)):

$$
\begin{aligned}
& \llbracket \text { what John ordered } \rrbracket= \\
& i X[\operatorname{ordered}(j, X) \wedge \forall Y(\operatorname{ordered}(j, Y) \rightarrow Y \leqslant X)]
\end{aligned}
$$

The last type-shifting step is invisible in English, but it is visible in Greek which uses the definite article o. Hence Greek offers direct empirical evidence for the maximality type shifter posited by Jacobson, and the FR is interpreted as a maximal plural definite (with the caveat about existence that we noted in the previous subsection.)

We illustrate now the derivation for the simple FR wh-opjos 'who', building on the analysis of Jacobson's which, as Jacobson suggests (2005: section 2) can be seen as a variant of the Comp analysis (see originally Groos and van Riemsdijk 1981). Recall that in Greek we have the option of having FC-FR with or without -dhipote, an option that does not, under normal circumstances, exist in English (whoever came to the party versus * who came to the party). Naturally, the wh-ever in English will encompass both Greek paradigms. The derivation of the regular FR will closely follow Jacobson's analysis with the wh-phrase denoting a set of individuals, Greek $o$ being the iota, and no intensionalization; the -dhipote wh-FR will be derived compositionally from it.

In our notation below we use lower case individual variables instead of Jacobson's set variables, assuming that $x$ may be a plural entity (atomic entities being a subcase thereof, again following Jacobson). We will also take it that the contribution of the relative wh-pronoun is to trigger the $\lambda$-abstraction rule of Heim and Kratzer's (1998: 96, rule (15)), and that C itself is semantically vacuous, unlike, for example, the interrogative $\mathrm{C}$. We will see cases, however, in the next subsection where $\mathrm{C}$ actually hosts free choice complementizers. 
(52) FR without -dhipote

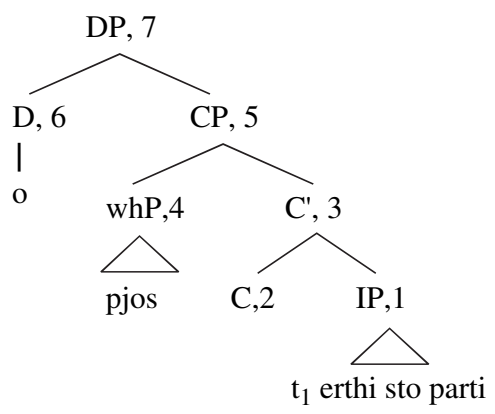

1. $\llbracket \mathrm{IP} \rrbracket=$ came.to.party $\left(t_{1}\right)$

2. $\llbracket \mathrm{C} \rrbracket=\lambda p \cdot p \quad$ (identity function)

3. $\llbracket \mathrm{C}^{\prime} \rrbracket=$ came.to.party $\left(t_{1}\right)$

4. $\llbracket$ pjos $\rrbracket=$ no denotation of its own; it triggers $\lambda$-abstraction by predicate abstraction (Heim and Kratzer 1998: 96)

5. $\llbracket \mathrm{CP} \rrbracket=\lambda x$.came.to.party $(x)$; or $\lambda x[P(x) \wedge \forall y(P(y) \rightarrow y \leqslant x)]$. The second formulation makes explicit the fact that $x$ may be a plural individual. Keeping this in mind, in our derivation we will henceforth adhere to the simpler clause for simplicity (see also Rullmann 1995).

6. $\llbracket o \rrbracket=\lambda P l(\lambda x . P(x))$

Here $o$ is treated as the maximality operator on the set characterized by the IP of the free relative (and not as a variable binder, as in Jacobson's formula that we gave earlier (51).

7. $\llbracket \mathrm{DP} \rrbracket=\llbracket o \rrbracket(\llbracket \mathrm{CP} \rrbracket)=\lambda P \quad l(\lambda x \cdot P(x))(\lambda x . \operatorname{came} \cdot \operatorname{to} \cdot \operatorname{party}(x))=$ $l(\lambda x$.came.to.party $(x))$

In clarification of the final steps 6, 7, given Jacobson's assumptions, $\lambda x$.came.to.party $(x)$ will be a singleton set consisting of a plural entity comprising all individuals that have the property that they came to the party. When $l$ applies to this set, the result is to create the plural individual that corresponds to this set. The $l(\lambda x$. came.to.party $(x))$ in the actual world $w_{0}$, will give us the maximal set of individuals that came to the party in $w_{0}$. This indeed seems to be the meaning of the plain FR in Greek.

\subsection{Adding free choice to the free relative}

We take it here that the composition of wh+ dhipote happens in the morphology (since syntactically the units are indistinguishable), and that 
it is compositional application of dhipote to the CP derived after application of predicate abstraction with the rule triggered by pjos. This is illustrated in the steps 6 and 7 below, with the addition of the FC-CP node; pjos further moves into the FC node and we get the right linear order:

(53) Free choice FR

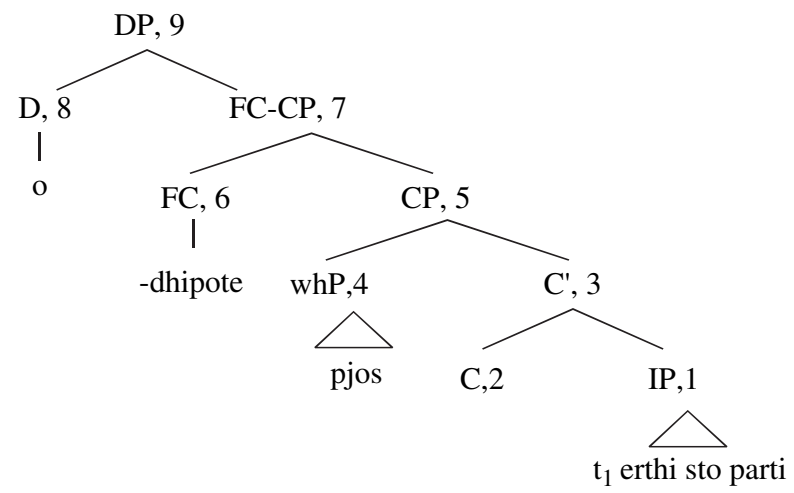

1. $\llbracket \mathrm{IP} \rrbracket=$ came.to.party $\left(\mathrm{t}_{1}\right)$

2. $\llbracket \mathrm{C} \rrbracket=\lambda p \cdot p \quad$ (identity function)

3. $\llbracket \mathrm{C}^{\prime} \rrbracket=$ came.to.party $\left(t_{1}\right)$

4. $\llbracket$ pjos $\rrbracket=$ no denotation of its own; it triggers $\lambda$-abstraction by predicate abstraction (Heim and Kratzer 1998: 96)

5. $\llbracket \mathrm{CP} \rrbracket=\lambda x$.came.to. $\operatorname{party}(x)$

Thus far the derivation proceeds exactly as in the case of the plain FR we just discussed. Now, we add FC:

6. $\llbracket$-dhipote $\rrbracket=\lambda P_{<s, e t>} \lambda w \lambda z . P(z)(w)$

This would require lifting first the CP property $\lambda x$.came.to. $\operatorname{party}(x)$ to its intension $\lambda w \cdot \lambda x$. came.to.party $(x)(w)$. After this is done (and we may assume an additional node for it, though we do not illustrate here), we get:

7. $\llbracket \mathrm{FC}-\mathrm{CP} \rrbracket=\llbracket$-dhipote $\rrbracket(\llbracket \mathrm{CP} \rrbracket)=$ $\lambda P_{<s, \text { et }} \lambda \boldsymbol{\lambda} \lambda z \cdot P(z)(w)(\lambda w . \lambda x$.came.to.party $(x)(w))=$ $\lambda w \lambda x$.came.to.party $(x)(w)$.

This is the intensional FC-FR set, namely the intension of the set characterized by the FR predicate. It can thus apply to any possible world $\mathrm{w}$ yielding the individuals that have the $\mathrm{CP}$ property in that world. If applied to the actual world the function will naturally yield the set of individuals that came to the party in the actual world.

The input to iota will thus now be of type $<s$, et $>$. 
8. $\llbracket o \rrbracket=\lambda P_{<s, e t>} l(\lambda w \lambda x \cdot P(x)(w))$

9. $\llbracket \mathrm{DP} \rrbracket=\llbracket \circ \rrbracket(\llbracket \mathrm{FC}-\mathrm{CP} \rrbracket)=$

$\lambda P_{<s, \text { et> }>l} l(\lambda w \lambda x \cdot P(x)(w))(\lambda w \lambda x$.came.to.party $(x)(w))=$

$l(\lambda w . \lambda x$.came.to.party $(x)(w))$

Hence the wh-FR opjosdhipote IP denotes a maximal sum, and, let us again repeat, in an extensional (episodic) sentence, $l(\lambda w \lambda x$.came. to.party $(x)(w))$ will apply to the actual world $w_{0}$, giving us the maximal set of persons that came to the party in $w_{0}$, just like with the plain FR. However, because the input of $l$ is a function from worlds to sets of individuals (characterized by a given property $P$ in those worlds), inside the FC-set there will be actual as well as possible individuals (more accurately, world-individual pairs). It is this that gives the distinctive domain extension FC flavour to the FR, since we may consider individuals also in less stereotypical or accessible alternatives.

At the same time, as we said, the FC-FR can be used in an episodic context and be quantified over. This is the case of subtrigging that we discuss next. In the derivation of the FC-FR the $w$ variable remains dependent because it is bound by $\lambda$, and not because it remains unbound as the $\mathrm{w}$ variable of the indefinite FCI in an episodic context. This explains why the FR will generally be licensed in episodic contexts (unlike the FCI indefinite), and we believe it captures accurately the way the FR, via subtrigging, actually rescues such structures.

Let us comment briefly on our final result. If our analysis of FC-FR is correct, then our account is consistent with Jacobson's suggestion that the FC-FR is really not so different from the plain one, certainly not in terms of quantificational force (Jacobson 1995: 479-481). According to Jacobson, what FC adds is broadening of the atomic domain; it is this broadening that we tried to capture in the formation of opjosdhipote that we proposed here.

As we are suggesting, the creation of this extended modalized domain of the FR carries with it a scalar inference. This can be viewed as a bottom of scale inference in that it allows us to include in the domain less likely or less prototypical individuals (cf. widening in the sense of Kadmon and Landman 1993). It can thus be seen as containing an even meaning which would be consistent with the observation that expressions corresponding to even, often with concessive meaning (see especially Lee 1997), and additive particles are used with FCI in many languages. Crucially, dōu in Mandarin is also used as even, a fact that fits nicely in this picture.

The low ranking inference, as we said, carries with it a concessive meaning roughly equivalent to no matter what/who which becomes particularly clear in cases of, for example, French FCIs like n'importe qui, 
and connects to the indiscriminative reading identified in Horn (2000a) that we mentioned earlier. In Greek, the concessive flavour arises also when -dhipote is absent but some other concessive marker is used, e.g. the concessive ke an or modal ke na particles that can be added to the plain FR:

Opjos $\{\mathrm{ke}$ an/ke na $\}$
who.FR and-if/and-subjunctive
efxaristithike.
was.happy.3sg
'Whoever came to the party had a good time.'

The FC flavour of this sentence is equivalent to its counterpart with -dhipote that we give below. It is probably this equivalence that explains the redundancy with-dhipote and $\{k e$ an/ke na\}:

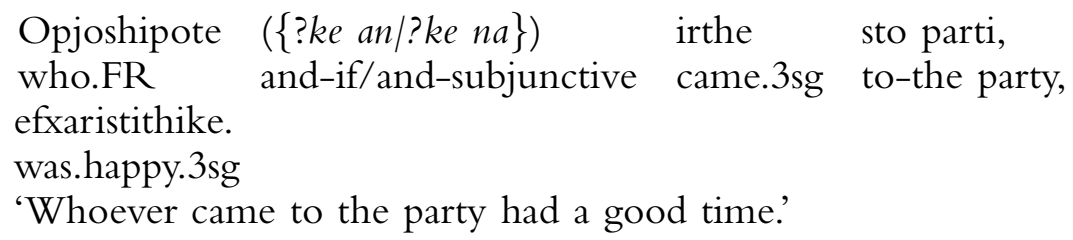

Given that ke an/ke na are complementizers in Greek (ke an introducing concessive sentences par excellence, i.e. 'even if', and na being the subjunctive complementizer), it can be argued in the light of the examples here that the FR complementizer is not semantically vacuous but quite the contrary: it can host FC modalization. This idea would further substantiate the intuition that FRs are really a wh-species distinct from the relative or interrogative, hence also in the function of their C. We will not pursue the details in this paper. We will just comment that, obviously, in the event FC happens at $\mathrm{C}$, the analysis we have proposed in (53) will have to be modified so as to capture the fact that $\mathrm{C}$, instead of FC-CP is the locus of FC application. Crucially, the fact that free choice can happen at $\mathrm{C}$ follows only under the Comp analysis of FRs that we adopt (and for which Jacobson 1995 argued extensively), and remains problematic for the competing Head analysis of FRs (Bresnan and Grimshaw 1974) which expects $C$ to be vacuous. Hence the facts here can ultimately be used as an argument in favour of the Comp analysis, a welcome result from this perspective.

\subsection{Wh-ever and a reconsideration of sub-trigging}

The two things that we noted about wh-ever were first that it occurs mainly as an FR creating subtrigging in episodic contexts; hence it is not subject to licensing. Second, there is typically no option of using 
bare $w h$ in FR in English: *who came to the party had a good time (with the exceptions that we noted earlier).

Subtrigging refers to a structure where the PI is followed by a relative clause in an episodic context, and generally has a rescuing effect, as we noted. For example, it allows any to appear in an episodic context that would otherwise rule it out, e.g. episodic perfective past.

(56) a. *Anyone brought a present.

b. Anyone who came to the party brought a present.

The fact that wh-ever, as opposed to opjosdhipote which can also take a nominal argument, typically forms an FR renders wh-ever structures exclusively subtrigging structures, thus making wh-ever a non-PI. Additionally, the absence of bare wh-FR in English renders wh-ever ambiguous between the FC and the non-FC FR we just discussed.

Dayal (1995), in her discussion of Hindi correlatives, and later Dayal (1998) in a discussion of FC-any analyses subtrigging as involving universal quantification over individuals. Quer (1998) and Giannakidou (2001), on the other hand, argue that subtrigging has a conditional structure and allows FCIs by satisfying non-veridicality. This analysis renders subtrigging parallel to the indefinite FC cases where a Q-operator binds a world variable. Subtrigged sentences will then have the following analysis given what we have said so far:

(57) a. I ate whatever he cooked.

b. I ate anything he cooked.

c. Efaga otidhipote majirepse. ate.1sg FCI-thing cooked.3sg

The FCI-nominal, i.e. anything in (57b), will be translated as a mere indefinite bound by the conditional universal quantifier:

(58) $\forall w, x$ [cooked (he, $x, w) \rightarrow$ ate $(\mathrm{I}, x, w)]$

This LF, augmented with the presupposition of exhaustive variation that we described in section 3, captures the universal-like meaning of any without analyzing it as a universal (unlike Dayal). When we think of the sentences with the FC-FRs, however, two possible analyses of subtrigging emerge. One will be to stick to the conditional structure of Giannakidou and Quer. In this analysis we will have the following LFs:

Greek (57c) with FC-FR

$\forall w, x\left[x=l\left(\lambda w^{\prime} \lambda z \cdot \operatorname{cooked}(\mathrm{he})(z)\left(w^{\prime}\right)\right) \rightarrow\right.$ ate $\left.(\mathrm{I}, x, w)\right]$, where

$w^{\prime}$ is a world accessible from $w$, including $w$ itself 
(60) English (57a) with wh-ever FR: ambiguous:

a. $\forall w, x[x=\imath(\lambda z \operatorname{cooked}(\mathrm{he})(z)(w)) \rightarrow$ ate $(\mathrm{I}, x, w)]$ $=$ the meaning of the plain Greek FR, derived as in (52)

b. $\forall w, x\left[x=\imath\left(\lambda w^{\prime} \lambda z\right.\right.$. cooked $($ he $\left.)(z)\left(w^{\prime}\right)\right) \rightarrow$ ate $\left.(\mathrm{I}, x, w)\right]$, where $w^{\prime}$ is a world accessible from $w$, including $w$ itself $=$ the meaning of the FC-FR in Greek, derived as in (53)

The other possible analysis will be to derive subtrigging directly from the FR meanings of plain and FC-FRs we have described in this section. The extensional FR, as we said, is expected to be fine in all episodic contexts, since when applied to the actual world, the iota function will give us the maximal plural entity that satisfies the predicate denoted by the FR CP in the actual world. Interestingly, the intensional FC-FR should also be fine in an extensional/episodic sentence, but making us think of possible individuals-what we have described as the broadening scalar effect. This explains easily why FC with clausal structure defies episodicity without appealing to the conditional rule and makes the analysis simpler.

Hence we distinguish FC-FRs, which are not really licensed, from indefinite FCI-nominals, which are (because they need their dependent $w$ variable to be bound by an operator), by appealing to their compositions directly. With the latter, we expect the conditional to create the appropriate context for binding the $w$ variable, hence the need for anti-episodicity; but in the former, there is no such need. Interestingly, the difference between FCI nominal any and its subtrigged incarnation renders this item ambiguous in the way Greek opjosdhipote is, between a derivation yielding an indefinite (as a FCI nominal) and one yielding a definite FCI, which is not subject to licensing and which would be parallel to the FC-FR. Would that mean that FC any is lexically ambiguous between a definite and an indefinite? Not really. Just as in the Greek case, definiteness or indefiniteness is not a case of lexical ambiguity, but of ambiguous syntax: it relies on whether the FC-phrase is closed under an indefinite or a definite function (derived as in (35) versus (53) respectively). The free choice core is intensionality, which is derived identically in both cases.

Now, when we further consider the difference between plain versus FC-FRs with wh-ever, we must note that it is the possible interpretation of wh-ever as a non FC-FR that explains why wh-ever can be used in episodic sentences receiving the so-called ignorance readings:

(61) a. Whichever woman is the editor of this magazine got a prize last night. 
b. Whichever movie Avon is playing right now is boring. (from Jacobson 1995)

The above sentences are about one particular woman and one particular movie respectively, and they express ignorance in that the speaker does not know exactly what the movie is or who the woman is (see Tredinnick 1994 for a discussion of similar cases in English that she labels don't know readings; see also von Fintel 2000). Dayal (1995) presents similar examples with Hindi correlatives which routinely receive such readings:

(62) Jo bhii laRkii vahaa khaRii hai vo Ravi kii dost hai. which ever girl there standing is she Ravi's friend is ' $\{$ ? Whichever girl is standing there/The girl standing there $\}$ is Ravi's friend.'

These ignorance contexts are episodic, and in this particular case also deictic. The fact that wh-ever is fine in such cases is consistent with its being interpreted as an extensional individual, i.e. under the expected bare FR interpetation we have illustrated in (52). Hindi correlatives and English -ever FRs can thus be directly interpreted this way-though English whichever more marginally so in the deictic context, as we see above. ${ }^{11}$ Yet the Greek FRs with FCIs are hopelessly odd in this context:

\begin{tabular}{|c|c|c|c|c|}
\hline $\begin{array}{l}\text { \#Opjac } \\
\text { FII }\end{array}$ & $\begin{array}{l}\text { ote jineka } \\
\text { woman }\end{array}$ & $\begin{array}{l}\text { ine } \\
\text { be. } 3 \mathrm{sg}\end{array}$ & $\begin{array}{l}\mathrm{i} \text { arxisindaktria } \\
\text { the editor }\end{array}$ & $\begin{array}{l}\text { aftou } \\
\text { this.gen }\end{array}$ \\
\hline the gen & $\begin{array}{l}\text { periodikou, } \\
\text { magazine.gen }\end{array}$ & & & \\
\hline & ena & $\begin{array}{l}\text { vravio } \\
\text { prize }\end{array}$ & $\begin{array}{l}\text { xthes } \\
\text { last }\end{array}$ & \\
\hline
\end{tabular}

'Whichever woman is the editor of this magazine got a prize last night.'

b. ?\#Opjodhipote koritsi stekete eki ine fili FCI girl stand.3sg there be.3sg friend tou Jani. the.gen John.gen.

' $\{$ ? Whichever girl is standing there/The girl standing there $\}$ is Jani's friend.'

\footnotetext{
${ }^{11}$ A reviewer suggests that what makes whichever girl is standing there slightly odd is that it is unlikely that one is in a position to know that a girl is standing there without being able to identify her. Compare with the following which are fine exactly because identification is possible:
}

(i) a. Whichever one of my roommates had a late snack (here) left a mess.

b. Whichever girl is standing outside my window is yelling too loudly. 
The oddity of the Greek examples is due to a conflict between the deictic reference imposed by the context and the FC result of having an intensionalized property as the input to iota. Consider what the sentence (63b) actually says:

(64) friend.of.John's $(l(\lambda w \lambda z$.woman-standing.there $(z)(w)))$

The property $\lambda w \lambda z$.woman-standing.there $(z)(w)$ will include actual as well as possible individuals in it, as we said earlier. So iota will create the complex individual that contains these individuals (or world-individual pairs). But this is too big an individual in the deictic context employed, and certainly not the one intended, hence the oddity. Note, crucially, that it is indeed a sort of deviance that we are talking about here, and not crude ungrammaticality.

On the other hand, with generic present tense or with the addition of a Q-adverb, the sentences become fine; and then, of course, we no longer talk about a particular woman or a particular girl (in fact the case of girl is neutral with respect to number, i.e. it can be more than one girl at a time standing there, as expected since there is no uniqueness condition in 'standing there', unlike with being the editor of a magazine):

(65)

Opjadhipote jineka ine i arxisindaktria aftou
FCI woman be.3sg the editor
to periodikou, perni sinithos pola vravia.
the.gen magazine.gen, get.3sg usually many awards.

'Whichever woman is the editor of this magazine usually gets a lot of prizes.'

(66) Opjodhipote koritsi stekete eki ine sinithos fili FCI girl stand.3sg there be.3sg usually friend tou Jani.

the.gen John.gen

'Whichever girl stands there is usually Jani's friend.' ('there' is a meeting point for Jani's friends).

This exclusive compatibility with only generic readings is expected if Greek FC-FRs are intensional FCIs only, as we are arguing here, and must be quantified over. These sentences would have structures parallel to the ones in (59) but with the respective Q-operators:

(67) USUALLY $w, x\left[x=\imath\left(\lambda w^{\prime} \quad \lambda z \cdot \operatorname{woman}(z)\left(w^{\prime}\right) \wedge\right.\right.$ editor.of.this. magazine $\left.(z)\left(w^{\prime}\right)\right)$; gets.many.prizes $\left.(x, w)\right]$, where $w^{\prime}$ is a world accessible from $w$, including $w$ 
(68) USUALLY $w, \quad x\left[x=\imath\left(\lambda w^{\prime} \quad \lambda z \cdot \operatorname{girl}(z)\left(w^{\prime}\right) \wedge\right.\right.$ standing.there $\left.(z)\left(w^{\prime}\right)\right)$; friend.of.Johns $\left.(x, w)\right]$, where $w^{\prime}$ is a world accessible from $w$, including $w$

And these, of course, are not cases of subtrigging (which characterizes episodic contexts) but regular quantified structures. Again, it is worth emphasizing that Greek does not allow ignorance readings of opjoshipote FRs, a fact supporting the idea that we are dealing with a real ambiguity in English and the other languages that allow both readings.

To sum up, in section 4 we have shown that we need to separate a definite-like (maximal) FC meaning, and, in the cases we looked at, this meaning is a result of FCIs occuring in FR structures. The FC morpheme intensionalizes the wh-phrase by adding a $\mathrm{w}$ variable to it, and this variable remains bound by the $\lambda$ operator. Unlike with nominal FCIs, the intensionalized wh-property in the FC-FR is the input to an iota type shifter, contributed by the definiteness marker $o$, and the FC-FR denotes a maximal intensional plural. Our analysis stayed close to Jacobson's at every step, spelling out precisely the contribution of FC, and offered a straightforward way of capturing the difference between Greek FC-FRs and wh-ever in English, as well as a core similarity, i.e. that they are not polarity sensitive the way indefinite FCIs are. As an additional welcome result, the account enabled a novel look at subtrigging by doing away with the conditional analysis, since it derived the non-polarity status of FC-FRs in episodic contexts by appealing directly to the FR denotation.

We are now in position to examine the Chinese nă-CL FCI which provided part of the motivation for initiating a definite analysis for FCIs.

\section{$5 \quad$ Nă-CL NPs AND CHINESE FCIs}

What we have seen in Greek FCIs is a distinction between indefinite FCIs (FCI-nominal) and definite FCIs (FC-FRs). The definiteness distinction is thus reflected in a distinction in the type of arguments that the FC takes. In Mandarin Chinese, as we will show, the definiteness distinction is also found, but it does not correspond to a difference in the type of arguments. Rather, it is the presence or absence of $d \bar{o} u$ that makes it visible. We propose that $d \bar{o} u$ in Chinese expresses the iota operator (corresponding to $o$ - in Greek), and the intensionality in FCIs in Chinese comes from a possibly covert wúlìn 'no matter'.

As we noted in section 1 already, the licensing of nă-CL NP 'which NP' in Chinese is not the same as the licensing of typical 
$w h$-indeterminates (such as bare $w h$ ); nor is it the same as the non-whFCI rènhé-NP 'any NP' (see Cheng and Giannakidou 2005). Bare wh's behave like PIs in Chinese (see Cheng 1991, Li 1992, Lin 1998) and they can also be interpreted as FCIs, which contrasts with rènhé NPs, which are always interpreted with free choice meaning. We will not repeat the data here, but see Cheng and Giannakidou (2005) for an extensive comparison between $n \breve{a}-\mathrm{CL} \mathrm{NP}$ and the other paradigms. We do want to add the observation that $n \breve{a}$-CL NP as FCI exhibits a more limited distribution than that of the Greek FCI: it is only licensed in modal contexts, as can be seen in Table 2 .

We also see in Table 2 that FC readings are available for other whparadigms in Chinese, which end up behaving like PIs as a class. Clearly, we want to explain why the definite form năa-CL NP exhibits the limited distribution it does; for now, however, we will leave this question open.

We will concentrate here on the behaviour and properties of nă-CL NPs and what they can tell us about the ingredients of FCIs in Chinese (in comparison with Greek).

Table 2 Chinese FCIs.

\begin{tabular}{lccc}
\hline Environments & bare $w h$ & $n \breve{a}-\mathrm{CL}$ & rènhé-NP \\
\hline 1. Episodic negation & $\mathrm{OK}$ & $*$ & $\mathrm{OK}$ \\
2. Episodic questions & $\mathrm{OK}$ & $*$ & $\mathrm{OK}$ \\
3. Conditionals & $\mathrm{OK}$ & $\mathrm{OK}$ & $\mathrm{OK}$ \\
4. Restriction of universal & $*$ & $*$ & $\mathrm{OK}$ \\
5. Future particle/will & $*$ & $*$ & $\mathrm{OK}$ \\
6. Modal verbs & $\mathrm{OK}^{\wedge}$ & $\mathrm{OK}^{\wedge}$ & $\mathrm{OK}$ \\
7. Directive intensional verbs & $*$ & $*$ & $*$ \\
8. Imperatives & $*$ & $\mathrm{OK}$ & $\mathrm{OK}$ \\
9. Habituals & $\mathrm{OK}^{\wedge}$ & $*$ & $\mathrm{OK}$ \\
10. Stative verbs & $*$ & $*$ & $*$ \\
11. Generics & $\mathrm{OK}^{\wedge}$ & $*$ & $*$ \\
12. NP-comparatives & $\mathrm{OK}^{\wedge}$ & $\mathrm{OK}^{\wedge}$ & $\mathrm{OK}$ \\
13. only/zhi & $*$ & $*$ & $\mathrm{OK}$ \\
14. Negative factives & $*$ & $*$ & $*$ \\
15. Affirmative episodic sentences & $*$ & $*$ & $*$ \\
16. Existential constructions & $*$ & $*$ & $*$ \\
17. Epistemic intensional verbs & $*$ & $*$ & $*$ \\
18. Progressives & $*$ & $*$ & $*$ \\
19. Non-negative factive verbs & $*$ & $*$ & $*$ \\
\hline
\end{tabular}

$\mathrm{OK}^{\wedge}$ : indicates $\mathrm{OK}$ in cases which there is fronting plus $d \bar{o} u$. 


\subsection{Definite vs. indefinite FCIs in Chinese}

Though nă-CL NP is more restricted in its distribution, it is similar to other FCIs in that it does not necessarily require $d \bar{o} u$ in order to have a free choice reading (see Cheng and Giannakidou 2005 for more details). Consider the following sentences:

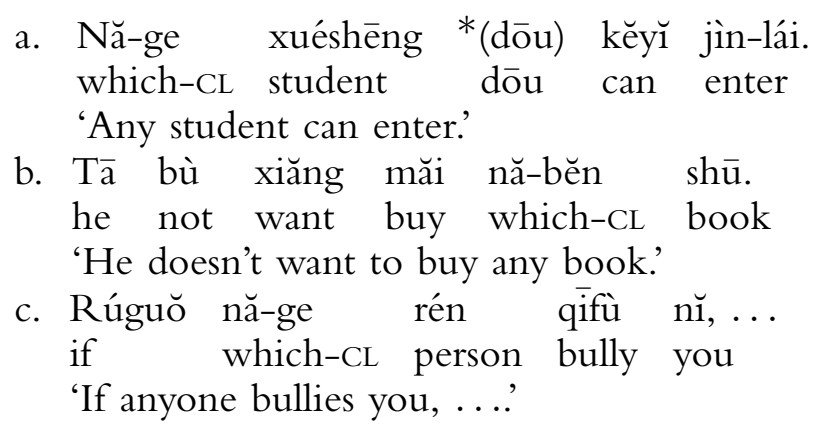

The sentences in $(69 \mathrm{~b}-\mathrm{c})$ show that $d \bar{o} u$ is not obligatory. Dōu appears to be obligatory with the modal keеy $\breve{l}^{\prime}$ 'can', as we can see also from (70):

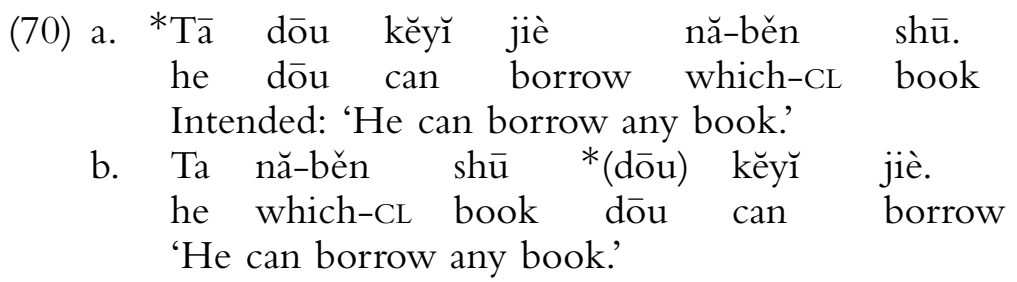

Nă-bèn sh̄̄ 'which book' cannot stay in its canonical object position when it appears under the modal ké y $\breve{l}$ 'can', but must front to a pre$d \bar{o} u$ position. ${ }^{12}$ In (70b), do $u$ is obligatory.

One may ask whether or not $d \bar{o} u$ can appear in sentences such as (69b) and (69c). The answer is yes. The question which arises then is whether there is any difference between $n \breve{a}$-CL NP with $d \bar{o} u$ and $n \breve{a}$-CL NP without $d \bar{o} u$. To answer this question, consider first the sentences in (71), which are comparable to the pair we discussed earlier about English and Greek:

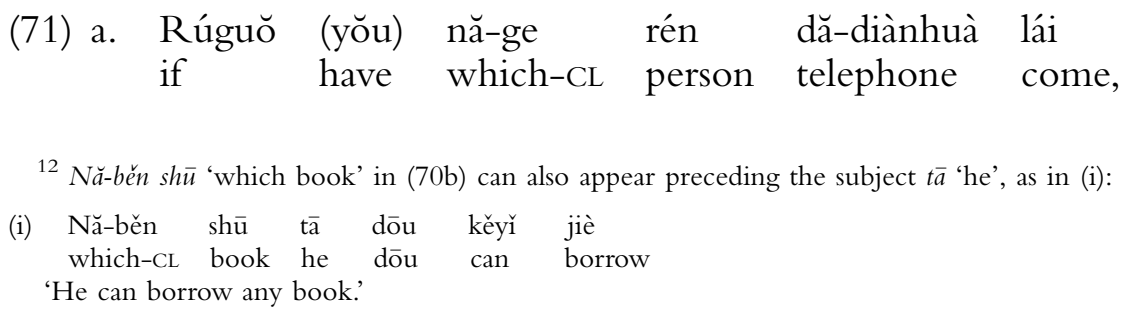




$\begin{array}{lllll}\text { jiù } & \text { suō } & \text { wŏ } & \text { bù } & \text { zài. } \\ \text { then } & \text { say } & \text { I } & \text { not } & \text { be }\end{array}$

'If anyone calls, say that I'm not here.'

b. (wúlùn) nă-ge rén dă-diànhuà lái, wŏ no-matter which-CL person telephone come I. dōu bù zài

all not be

'Whoever calls, I'm not here.'

Though both sentences are grammatical, (71a) cannot be used in situations in which the phone is ringing. It seems then that $d \bar{o} u$ contributes the tendency observed for the definite plurals and FR, namely to exclude the empty set. In fact, there is no necessary expectation of a call in (71a) while in (71b) there is. (72a, b), with bare $w h$-forms, further illustrate this difference:

(72) a. Tā bù xiăng qù năr.

he not want go where

'He does not want to go anywhere (in particular).'

b. Tà năr dōu bù xiăng qù.

he where dōu not want go

'He does not want to go anywhere what-so-ever/at all.'

In (72a), the bare wh năr 'where' appears under negation. This sentence can be used in cases where there isn't anywhere in particular or special that he wants to go to (though he may indeed want to go some place or other). In contrast, (72b) means that there is absolutely no place, of a contextually determined set of places, that he wants to go. Again, we have the flavor of wanting to exclude the empty set that comes with definite-like expressions.

The same contrast can be shown with (69b), repeated in (73a), in contrast with (73b):

(73) a. Tā bù xiăng măi nă-běn shū.

he not want buy which-CL book

'He doesn't want to buy any book (in particular).'

b. Tā nă-běn shū dōu bù xiăng măi.

he which-CL book all not want buy

'He does not want to buy any book at all.'

(73a), without $d \bar{o} u$, can be interpreted as 'he does not want to buy any particular book'; but (73b) can only be interpreted as 'there is absolutely no book what-so-ever (from a contextually determined set) that he wants to buy. In (73a) there is no contextually determined set of books that we are talking about. 
If this characterization of the difference between FCIs with $d \bar{o} u$ and FCIs without $d \bar{o} u$ is correct, it appears that $d \bar{o} u$ contributes to the definiteness and exhausitivity of the FCIs. We can then ask how that is done. From Greek definite FCIs, we see that there are two necessary ingredients: intensionality and the maximal sum formation (iota). The question then is where these ingredients are to be located in the Chinese definite FCIs.

To answer the first question, we follow Lin (1996) who analyses all $d \bar{o} u$ sentences as wúlùn. . .dōu sentences (wulun = regardless). In other words, typical $d \bar{o} u$ sentences are just elliptical wúlùn. . .dōu sentences. ${ }^{13}$ There are thus two kinds of wúlùn ... dōu sentences. One is clausal and one is nominal (examples and translations from Lin 1996) (note that regardless of whether wúlun takes a nominal or a clause, do $u$ is present):

$$
\begin{aligned}
& \text { a. (Wúlùn) shéi dōu kĕy̆ lái. } \\
& \text { no-matter who dōu can come } \\
& \text { 'No matter who can come.' } \\
& \text { b. (Wúlùn) nı̆ zuò shěnme, wŏ dōu méi yìjiàn } \\
& \text { no-matter you do what I dōu not opinion } \\
& \text { 'No matter what you do, I won't have an opinion.' }
\end{aligned}
$$

Note that wúlun 'no matter/regardless' is optionally present; note also that the above examples contain a bare wh-word. According to Lin (1996), " "... the function of wulun is to form the generalized union over the set of propositions, i.e., the set of sets of situations, denoted by the wh-clause following it." (p. 76) We propose that wúlun (overt or covert) is actually the element that provides the intensionalization, along with the presupposition of exhaustive variation (which as we said in section 3.2 corresponds to a universal statement about $\mathrm{i}$-alternatives, bringing our analysis close to Lin's). So we take the meaning of wúlùn 'no matter/regardless' to be equivalent to that of the Greek intensionalizer -dhipote:

(75) wulun $\rrbracket=\lambda P_{<s, \text { et }>} \lambda w \lambda x . P(x)(w)$

$D \bar{o} u$, on the other hand, is a generalized distributive operator in Lin's analysis. In the case of wúlùn ... dōu, it distributes over the set of situations in the generalized union corresponding to the denotation of the wuilin-clause. In our analysis, this gets translated into a claim

\footnotetext{
${ }^{13}$ Though we are not entirely convinced that ALL dōu sentences are elliptical wúlìn ... dōu sentences, we believe that the ones expressing FCIs must be; see Cheng and Giannakidou (2005) for more data and arguments for this.
} 
that $d \bar{o} u$ is the iota operator (like the definite article $o$ in Greek). Here we define it as taking an intensionalized property as its input, since it is such a property that it combines with after application of wúlùn:

$$
\llbracket \mathrm{do} \mathrm{u} \rrbracket=\llbracket o \rrbracket=\lambda P_{<s, \text { et }} l(\lambda w \lambda x \cdot P(x)(w))
$$

$\bar{D} \bar{u}$ is made parallel to Greek $o$, though it might be more accurate to attribute to it both maximality and exhaustivity as we said earlier. We have not discussed the differences between the two in this paper, and we will therefore continue employing iota as a neutral term to cover both maximality and exhaustivity (see Cheng and Giannakidou (2005) for some more discussion). Extending our account, we claim that the strategy to employ focus particles (mo, bhii) in FCIs crosslinguistically reflects precisely this need in languages with whindeterminates: to create definite FCIs. At this stage, however, our claim remains at the level of speculation, since clearly more work needs to be done.

Now, wúlun composes with năa-CL, or a bare $w h-$, and the product is always an FC meaning. This means that wúlun is always present with $n \breve{a}-\mathrm{CL}$, as we suggested in footnote 13 already, but it is optionally present with bare $w h$. This, again, is how we relativize Lin's claim that all dōu sentences contain wúlùn.

Given what we said so far, the denotation of $n \breve{a}-C L+n o u n+d \bar{o} u$ is in fact always wúlùn+nă-CL+noun+dōu. This suggests the following composition parallel to opjosdhipote (without iota):

$$
\begin{aligned}
& \text { a. } \llbracket \text { na-ge ren } \rrbracket=\lambda w \cdot \lambda y \cdot \operatorname{person}(\gamma)(w) \\
& \text { b. } \llbracket \text { wulun } \rrbracket(\llbracket \text { na-ge ren } \rrbracket)=\lambda P_{<s, e t>} \lambda w \lambda x \cdot P(x)(w) \lambda w \cdot \lambda y \cdot \text { person } \\
& \quad(y)(w))=\lambda w \lambda y \cdot \operatorname{person}(y)(w)
\end{aligned}
$$

This intension of the person property is then the input to $d \bar{o} u$ :

$$
\begin{aligned}
& \llbracket \mathrm{do} u \rrbracket(\llbracket \text { wulun na-ge ren } \rrbracket)=\lambda P_{<s, e t>} l(\lambda w \lambda x \cdot P(x)(w))(\lambda w \lambda y . \\
& \text { person }(y)(w))=\imath(\lambda w \lambda y \cdot \operatorname{person}(\gamma)(w))
\end{aligned}
$$

The $\mathrm{w}$ variable of this intensional quantifier will be dependent, just like in the case of the Greek FCI-FR because it will be bound by the $\lambda$-operator under iota.

This analysis entails that what we see in the Greek morphology, we see in the syntax in Chinese. In Greek, the morphological composition of FCIs has a definiteness marker as well as the FC determiner-dhipote, providing the intensionality. Chinese on the other hand, does not have these ingredients in the morphological composition. Rather, they are 
present in the syntactic composition of FC, with wuilun...do $u$, providing the intensionalization as well as iota. ${ }^{14}$

There are two final things one may wonder about. First, why would a D-linked wh-phrase such as nă-CL NP 'which NP' require an additional element, i.e. $d \bar{o} u$ to express iota (or maximality). To answer this question, we note that the use of the D-linked wh-paradigm for definite FCIs does not exclude the use of $d \bar{o} u$; indeed, $d \bar{o} u$ provides the maximality needed, which the wh-phrase alone does not have. Moreover, when nă-CL NP appears without $d \bar{o} u$ (such as in cases under negation and in conditionals), we will then be dealing with an indefinite FCI. This is reminiscent of the Greek FCI nominal such as opjosdhipote, which may also be an indefinite FCI though $o$ - is also present.

Second, how come which-phrases in English are not FCIs? This question is particularly pressing in the context of Den Dikken and Giannakidou's (2002: 42) claim that which-phrases are presuppositional and cannot be used as PIs. In favour of this claim they illustrate, e.g. that the PI the hell cannot modify which-phrases: *which student the hell, or self-standing partitive which as in There are a lot of books on the tablewhich (*the hell) do you want? This observation, which correctly captures the fact that which-phrases in English are not PIs, raises a question about the consequences of our analysis: if which provides prime material for polarity FC status, then why is it that which-phrases in Chinese but not in English are FCIs?

To answer this question, the recent analysis of English which as a definite description in Rullmann and Beck (1998), and Beck and Rullmann (1999), will be relevant. These authors explicitly analyse which-phrases as definites, and propose the following denotation for which man:

(79) $\llbracket$ which $\operatorname{man}_{i} \rrbracket=$ the $\left(\lambda y\left[\operatorname{man}(y)(w) \wedge y=x_{i}\right]\right)$

The output of this function will be the unique individual that is a man in a given context. At the same time, the world variable $w$ can either be bound by the question operator in $\mathrm{C}^{0}$-in which case it acquires a dependent or intensional value-or it can be free in which case it is assigned the value of the actual world. Beck and Rullmann (1999) actually argue for this choice, and the difference is used to account for

\footnotetext{
${ }^{14}$ Chinese differs from Greek however, in that the Greek definite-o is present in all the FCIs, definite or indefinite alike; $d \bar{o} u$, in Chinese, however, is only present in the definite FCIs. Yet recall that in our derivation of the indefinite nominal FCI in section 3.1 we treated opjosdhipote as a lexical unit, thus blocking the contribution of $o$ in this case. In Chinese, the addition of $d \bar{o} u$ is the mechanism of switching from an indefinite to a definite FCI, suggesting that Chinese wh-elements are indeed indefinites inherently.
} 
de re and de dicto readings in intensional contexts. What matters for our purposes is that assimilation of a which-phrase to a definite is independently motivated.

If we compare Rullman and Beck's formula to our denotation of wúlùn nă-ge rén 'wúlùn which person' in (77), we see that the $w$ variable in wúlùn nă-ge rén 'wúlùn which person' is bound by the $\lambda$ and can thus not be free. This explains the fact that nă-CL nominal in Chinese is dependent but which man in English is not. And it is all due to the previous application of wúlun. Hence we predict the FCI polarity behavior of $n \breve{a}$-CL nominal (and its similarity to the Greek opjosdhipote), as well as the fact that English wh-phrases are not FCIs: their world variable is independent and can be assigned the actual world as its value, as argued in Beck and Rullmann.

But there is one remaining detail: nă-CL also has a regular interrogative meaning, and in this case the nŭa-set or individual can indeed be a set or an individual in the actual world. This means that, in order to derive the interrogative meaning of năa-CL, we need to admit that its w variable can also be independent. But then, how is it different from which in terms of polarity? The key lies in intensionalization: our crucial premise is that the intensionalization that derives free choice PI-status is done by wúlùn. With FCI nă-CL, wúlìn, we must argue, is always present, covertly or overtly, and restricts the w variable to dependent values only. In the interrogative use, there is no wúlin, thus no restriction on the values, just like with which.

To sum up, what we saw in this section was that our analysis, which postulates free choice intensionalization together with a core split between definite and indefinite FCIs in Greek, affords an accurate description of the distribution and interpretation of the novel FCI $n \breve{a}-\mathrm{CL}$ 'which' in Mandarin. We analysed $d \bar{o} u$ as a maximality operator (iota), and illustrated that depending on whether or not it appears with $n \breve{a}-\mathrm{CL}$, the item is interpreted as definite or indefinite. We also argued for an intensionalization process in the Mandarin FCI, akin to the function of -dhipote in Greek, and we held this intensionalization accountable for the polarity status of $n \breve{a}-\mathrm{CL}$.

\section{CONCLUSION}

One of the main conclusions to be drawn from this paper is that the link between wh-morphology and free choice supports the variable analysis of free choice phenomena (Giannakidou 1998, 2001; Horn $2000 \mathrm{a}, 2000 \mathrm{~b}, 2005)$. The novel refinement that we proposed is to 
acknowledge, next to the class of indefinite FCIs, a class of FCIs that behave like definites in denoting maximal plural entities. We showed that the contrast is syntactic, i.e. it correlates with whether or not the FCI contains an expression that contributes iota. Typically, closure under iota is a given in an FC free relative, hence FC free relatives present the standard case of what we take to be definite FCIs. In Mandarin, on the other hand, do $u$ modifies FCIs both with nominal or clausal complements, and in both cases it contributes maximality when it occurs.

Alternatively, any, and the Greek opjosdhipote taking a nominal argument, exhibit the case of indefinite FCIs familiar from the earlier literature (Giannakidou 2001, Horn 2001, 2005). The optionality of $d \bar{o} u$ in Mandarin was shown to reflect exactly the definite versus indefinite contrast we identified for any and Greek FCIs, and likewise, we suggested, the same distinction is expressed lexically in English between FCI nominal any versus wh-ever.

In this context, wh-phrases turn out to be good candidates for FCIs because they provide predicates upon which certain operations apply: intensionalization, and additionally either maximalization, or embedding under an indefinite determiner, as we proposed here for FCI nominals. We have given an explicit syntax-semantics for both definite and indefinite FCIs and illustrated that in both cases FCIs contribute a world variable that is dependent - either because it cannot remain free (indefinite FCIs), or because it remains bound by the $\lambda$-operator under iota (definite FCIs). This dependency is consistent with the view of PIs as lexically deficient expressions advocated in Giannakidou (1998, 2001) and constitutes an attempt to capture formally this deficiency.

Crucially, it is the presence of a dependent variable that renders a wh-phrase a polarity sensitive FCI and restricts its distribution in non-episodic contexts; our account thus captures easily the polarity behaviour of Greek and Chinese FCIs. At the same time, we also acknowledged the fact that clausal structure, as in the case of FC relatives and wh-ever, creates FCIs that are not subject to licensing, and derived their freer distribution by appealing directly to the meaning of the free relative. This enabled a simpler analysis of subtrigging, i.e. the occurrence of FC free relatives in episodic contexts, by using directly the meaning of the free relative.

Our initial observation was that the morphological make-up of wh-words that function as FCIs in Mandarin and Greek indicate that interrogative semantics alone cannot serve as the basis of free choice. Our findings, then, question Kratzer and Shimoyama (2002) which attempt to do precisely this. In the context of the facts 
that motivated our analysis, it is also hard to see how interrogative semantics alone can predict the polarity behavior of FCIs, or the observed difference between polarity and non-polarity FCIs. In fact, the non-polarity cases of FCIs that we discussed, which would fall indeed in the class described by Kratzer and Shimoyama, were shown to be free relatives, hence substantially different from interrogative structures.

We have not claimed to have provided answers to all questions that arise with free choice. In fact, we left some important questions open: for instance, the very restricted distribution of the definite $n \breve{a}$-CL NP in modal contexts, and the contrast in this respect with its Greek definite counterpart - the FC free relative-which exhibits the freer distribution of wh-ever, and can occur even in episodic sentences via subtrigging. Obviously, this contrast must be taken to suggest that definiteness in itself is neither a necessary nor a sufficient condition for a freer distribution of this class of FCIs. Apparently, the fact that we have free relative structures in the cases of Greek and wh-ever in English but not in Chinese plays a role, but we will not speculate further predictions beyond exactly this at the present stage. We also have not discussed how maximality and exhaustivity are to be linked in the analysis of $d \bar{o} u$, or how our analysis of $d \bar{o} u$ in Chinese can be extended to capture the contribution of related additive particles in other languages with wh-indeterminates, e.g. Japanese (dare) mo, Korean to and na (but see Park 2005 for a recent analysis of na as a definitenes marker in the spirit of our analysis here). Our hope has been to offer a plausible and flexible enough framework where such questions can indeed be addressed, and in future research, answered in a satisfactory way.

\section{Acknowledgements}

We would like to thank the anonymous reviewers of the Journal of Semantics for their very helpful insights and suggestions which led to considerable improvements in terms of both content and presentation. We are also grateful to the editor, Bart Geurts, for his observations and comments at every stage, which also proved instrumental to improving the paper. For discussions and additional suggestions, we would also like to thank Larry Horn, Chris Tancredi, Jason Merchant, Georges Tsoulas, and Jerry Sadock, Eri Vlachou and Jim Huang; Boya Li, Rint Sybesma, Dylan Tsai and Yang Shen for discussions on Chinese as well as help with Chinese data, as well as KookHee Gill and Eun-Hae Park for discussions on Korean that unfortunately didn't make it into the paper. Finally, we would like to thank the audience of the Workshop on Quantification at the University of York, UK (July 2004), where a preliminary form of this paper was presented. 
ANASTASIA GIANNAKIDOU

Department of Linguistics

University of Chicago

1010 E. 59th Street

Chicago, IL 60637, USA

giannaki@uchicago.edu

LISA L.-S. CHENG

Department of Linguistics/TW

Leiden University

P.O. Box 95152300 RA

Leiden, The Netherlands

LL.Cheng@let.leidenuniv.nl
First version received: 14.04 .05

Second version received: 20.10.05

Accepted: 13.12.05

Advance Access publication: 04.04.06

\section{REFERENCES}

Alexiadou, A. \& Giannakidou, A. (1998) 'Specificational pseudoclefts as lists'. In K. Shahin et al. (eds), Proceedings of WCCFL 17: 1-15.

Aloni, M. (2003) 'On choice offering imperatives'. In P. Dekker and R. van Rooy (eds), Proceedings of the Fourteenth Amsterdam Colloquium 14: 1-6.

Beck, S. \& Rullmann, H. (1999) 'A flexible approach to exhausitivity in questions'. Natural Language Semantics 7.3: 249-298.

Bolinger, D. (1977) Meaning and Form. Longman. London (Chapter 2, Any and some).

Bosque, I. (1996) La polaridad modal. Unpublished MS. University of Madrid.

Bresnan, J. \& Grimshaw, J. (1978) 'The syntax of free relatives in English'. Linguistic Inquiry 9: 331-391.

Cheng, L. L.-S. (1991) On the typology of Wh-questions. Ph.D. dissertation, Department of Philosophy and Linguistics, MIT (published by Garland, New York, 1997).

Cheng, L. L.-S. \& Giannakidou, A. (2005) 'The non-uniformity of whindeterminates with free choice in Chinese. To appear in G. Tsoulas and K.-H. Gill (eds), Strategies of Quantification. Selected papers from the workshop on Quantification and Crosslinguistic Variation, University of York. Oxford University Press.

Cooper, R. (1983) Quantification and Syntactic Theory. Reidel. Dordrecht.

Davison, A. (1980) 'Any as a universal or existential'. In J. van der Auwera (ed.) The Semantics of Determiners. Croom Helm. London., 11-34.

Dayal, V. (1995) 'Quanitification in correlatives'. In E. Bach et al. (eds.), Quantification in Natural Language. Kluwer. Dordrecht, 179-205.

Dayal, V. (1997) 'Free choice and -ever: identity and free choice readings'. Proceedings of Semantics and Linguistic Theory (SALT) VII: 99-116.

Dayal, V. (1998) 'Any as inherently modal'. Linguistics and Philosophy 21: 433-476.

Dayal, V. (2004) 'The universal force of free choice any'. In J. Rooryck (ed.) The Linguistic Variation Yearbook 4. John Benjamins. Amsterdam, 5-40.

Dikken, M. den \& Giannakidou, A. (2002) 'From Hell to Polarity: "Aggressively non-D-linked Wh-phrases as polarity items" '. Linguistic Inquiry 33: 31-61.

Donnellan, K. (1966) 'Reference and definite descriptions'. The Philosophical Review LXXV: 281-304. 
Enc, M. (1991) 'The semantics of specificity'. Linguistic Inquiry 22: 1-25.

Farkas, D. (2002) 'Varieties of indefinites'. Proceedings of Semantics and Linguistic Theory (SALT) 12: 59-83.

von Fintel, K. (2000) 'Whatever'. Proceedings of SALT 10: 27-40.

Giannakidou, A. (1997) 'Linking sensitivity to limited distribution: the case of free choice'. In P. Dekker et al. (eds), Proceedings of the 11th Amsterdam Colloquium. ILLC. University of Amsterdam, 139-145.

Giannakidou, A. (1998) Polarity Sensitivity as (Non)veridical Dependency. John Benjamins. Amsterdam.

Giannakidou, A. (1999) 'Affective dependencies'. Linguistics and Philosophy 22: 367-421.

Giannakidou, A. (2001) 'The meaning of free choice'. Linguistics and Philosophy 24: 659-735.

Giannakidou, A. (2002) 'Licensing and Sensitivity in Polarity Items: from Downward Entailment to (Non)veridicality'. In M. Andronis, A. Pycha \& K. Yoshimura (eds), CLS 38: Papers from the 38th Annual Meeting of the Chicago Linguistic Society, The Panels, 29-53.

Giannakidou, A. (2006) 'Only, emotive factive verbs, and the dual nature of polarity dependency'. To appear in Language 82.

Gill, K.-H., Harlow, S. \& Tsoulas, G. (2002) Disjunction, quantification, and free choice. Unpublished MS. University of York.

Groos, A., and van Riemsdijk, H. (1981) 'Matching effects in free relatives: a parameter in core grammar'. Proceedings of the Pisa Colloquium on Markedness, Annali dela Scuola Normale Superiora, Pisa, 171-216.

Grosu, A. (1996) 'The proper analysis of "Missing P" free relative constructions'. Linguistic Inquiry 27: 257-293.

Haspelmath, M. (1997) Indefinite Pronouns. Oxford University Press. Oxford.
Heim, I. (1982) The semantics of definite and indefinite noun phrases. Unpublished Ph.D. dissertation, University of Massachusetts. Amherst, MA.

Heim, I. (1992) 'Presupposition projection and the semantics of attitude verbs'. Journal of Semantics 9: 183-221.

Heim, I. \& Kratzer, A. (1998) Semantics in Generative Grammar. Blackwell. Oxford.

Horn, L. R. (1972) On the semantic properties of logical operators in English. Unpublished Ph.D. dissertation. University of California at Los Angeles.

Horn, L. R. (1997) ‘All John’s Children are as Bald as the King of France: existential import and the geometry of opposition'. Chicago Linguistics Society 33: $155-179$.

Horn, L. R. (2000a) 'Any and ever: Free choice and free relatives'. Proceedings of Israeli Association for Theoretical Linguistics 15: 71-111.

Horn, L. R. (2000b) 'Pick a theory: not just any theory'. In L. Horn \& Y. Kato (eds), Negation and Polarity: Syntactic and Semantic Perspectives. Oxford University Press. Oxford, 147-192.

Horn, L. R. (2005) 'Airport '68 Revisited: Toward a unified indefinite any'. In G. Carlson \& F. J. Pelletier (eds), The Partee Effect. CSLI. Stanford, 179-205.

Iatridou, S. \& Varlokosta, S. (1998) Pseudoclefts crosslinguistically. Natural Language Semantics 6.1: 3-28.

Jacobson, P. (1995), 'The quantificational force of English free relatives'. In Bach et al. (eds) Quantification in Natural Language. Kluwer. Dordrecht, 451-486.

Jayez, J. \& Tovena, L. (2005) 'Free choiceness and non-individuation'. Linguistics and Philosophy 28: 1-71.

Kadmon, N. \& Landman, F. (1993) 'Any'. Linguistics and Philosophy 16: 353-422.

Kamp, H. (1981) 'A theory of truth and semantic interpretation'. In 
J. Groenendijk et al. (eds), Formal Methods in the Study of Language: Proceedings of the Third Amsterdam Colloquium, Part I. Mathematical Centre Tracts. Amsterdam.

Kratzer, A. \& Shimoyama, J. (2002) Indeterminate pronouns, the view from Japanese. Unpublished MS. University of Massachusetts, Amherst, MA.

Krifka, M. (1995) 'The semantics and pragmatics of polarity items in assertion'. Linguistic Analysis 15: 209-257.

Krifka, M., Pelletier, F. J., Carlson, G., ter Meulen, A., Chierchia, G. \& Link, G. (1995), 'Genericity: an introduction'. In G. Carlson \& F. J. Pelletier (eds), The Generic Book. University of Chicago Press. Chicago, 1-124.

Lahiri, U. (1998) 'Focus and negative polarity in Hindi'. Natural Language Semantics 6: 57-23.

Larson, R. (1999) Free relative clauses and missing P's. Reply to Grosu. Unpublished MS.

Lee, C. (1997) 'Negative polarity and free choice: where do they come from?' In P. Dekker et al. (eds), Proceedings of the 11th Amsterdam Colloquium. ILLC, University of Amsterdam, 217-222.

Lee, Y.-S. \& Horn, L. R. (1994) Any as an indefinite plus even. Unpublished MS. Yale University.

LeGrand, J. E. (1975) Or and Any: The semantics and syntax of two logical operators. Unpublished Ph.D. dissertation. University of Chicago.

Li, Y.-H. A. (1992) 'Indefinite $W h$ in Mandarin Chinese'. Journal of East Asian Linguistics 1.2: 125-155.

Lin, Jo-Wang (1996), Polarity Licensing and Wh-phrase Quantification in Chinese. Unpublished Ph.D. dissertation. University of Massachusetts, Amherst, MA.

Lin, J.-W. (1998) 'On existential polarity wh-phrases in Chinese'. Journal of East Asian Linguistics 7: 219-255.
Nishigauchi, T. (1986) Quantification in syntax. Ph.D. dissertation. University of Massachusetts, Amherst, MA.

Quer, J. (1998) Mood at the Interface. Unpublished Ph.D. dissertation, University of Utrecht.

Quer, J. (1999) The quantificational force of free choice items. Unpublished MS. University of Amsterdam.

Quine, W. van O. (1960) Word and Object. MIT Press. Cambridge, MA.

Park, E.-H. (2005) Wh-indeterminates and free choice in Korean. Unpublished MS. University of Chicago.

Rullmann, H. (1996) Two types of negative polarity items. Proceedings of Northeastern Linguistics Society (NELS) 26: 335-350.

Rullmann, H. \& Beck, S. (1998) 'Presupposition projection and the interpretation of which-questions'. In D. Stgrolovitch and A. Lawson (eds), SALT VIII: 215-232.

Sæbø, K.-J. (2001) 'The semantics of Scandinavian free choice items'. Linguistic and Philolosophy 24: 737-787.

Tovena, L. \& Jayez, J. (1997) The modal arbitrariness of any. Unpublished MS. University of Geneva and EHESS, Paris.

Tancredi, C. \& Yamashina, M. (2004) Interpretation of indefinites in the Japanese wh-mo Construction. Paper presented in the Workshop on Quantification, York, July 2004.

Tredinnick, V. (1994) 'On the interpretation and distribution of -ever in English free relatives'. In R. Eckardt \& V. van Geenhoven (eds), Proceedings of CONSOLE 2: 253-268.

Vendler, Z. (1962) 'Each and every, any and all. Mind 71: 145-160.

Vlachou, E. (in preparation) Varieties of free choice. Ph.D. thesis, University of Utrecht.

Zimmerman, T. E. (2000) 'Free choice disjunction and epistemic possibility'. Natural Language Semantics 8: 255-290. 